IFN Working Paper No. 1009, 2014

\title{
Real-time versus Day-ahead Market Power in a Hydro-based Electricity Market
}

Thomas P. Tangerås and Johannes Mauritzen 


\title{
Real-time versus day-ahead market power in a hydro-based
}

\section{electricity market*}

\author{
Thomas P. Tangerås ${ }^{\dagger}$ and Johannes Mauritzen ${ }^{\ddagger}$
}

June 27, 2014

\begin{abstract}
We analyse in a theoretical framework the link between real-time and day-ahead market performance in a hydro-based and imperfectly competitive wholesale electricity market. Theoretical predictions of the model are tested on a detailed data set of trades and prices from the Nordic power exchange, Nord Pool Spot. We reject the hypothesis that prices were at their competitive levels throughout the period under examination. An exogenous change in the number of price areas in Sweden in November of 2011 is used for identification.
\end{abstract}

Key Words: Hydro power, market power, Nord Pool Spot.

JEL codes: D43, D92, L13, L94, Q41.

*Many thanks to Hunt Allcott, Fridrik Baldursson, Torstein Bye, Ewa Lazarczyk, Matti Liski, Mar Reguant, an anonymous referee and participants at the NEECI workshop in Helsinki for their helpful comments. We are particularly grateful to Erik Lundin for sharing the "Urgent Market Messages" dataset which we employ in the paper. This research was financed within the IFN research program "The Economics of Electricity Markets"; see www.ifn.se/eng/research/the_economics_of_electricity_markets.

${ }^{\dagger}$ Corresponding author. Research Institute of Industrial Economics (IFN), P.O. Box 55665, 10215 Stockholm, Sweden. E-mail: thomas.tangeras@ifn.se.

${ }_{\ddagger}^{\ddagger}$ Norwegian School of Economics (NHH), Department of Business and Management Science, Helleveien 30, 5045 Bergen, Norway. E-mail: johannes.mauritzen@nhh.no 


\section{Introduction}

Wholesale electricity markets typically are concentrated: A small number of power companies control the bulk of generation capacity, transmission bottlenecks constrain import possibilities, and there are economical and political barriers to large scale entry. Demand is insensitive to short term changes in prices because household consumption mostly responds to monthly or yearly

price averages. Concentrated markets with price inelastic demand are susceptible to the exercise of market power whereby producers behave strategically to raise profits. The performance of liberalized electricity markets therefore poses a major concern to competition authorities and other market monitors.

Hydro power stands for more than half of the annual electricity production in more than one third of the countries in the world (Førsund, 2007). A problem of evaluating market performance in electricity markets which rely heavily on hydro power stems from the fact that hydro marginal costs are problematic to estimate for outside observers. In a hydro power plant, the decision problem facing management is how much of the plant's reservoir to release today and how much to save for future production. The marginal production cost in a hydro power plant consists mainly of this opportunity cost of water, the so-called water value. The water value depends on management's expectations about the future value of the resource. Hence, it is impossible to infer directly whether a hydro power plant running below full capacity sets competitive prices or exploits market power.

We illustrate in a theoretical model the challenge of detecting market power in a hydrobased electricity market. Hydro power production is a resource extraction problem. Hence, the equilibrium condition is a generalization of the Hotelling rule, which in its most basic form states that the price of a natural resource evolves proportionally to the real interest rate of return (which in day-to-day operations can be set equal to zero). Imperfect competition and uncertainty imply that the firm in our setting equates expected marginal revenue across time instead of expected prices. If the decision maker maximizes expected utility instead of expected profit, then resource extraction is adjusted by a risk correction factor, the magnitude of which depends on the correlation between consumption and marginal revenue. In addition, resource extraction is limited by production and/or reservoir constraints. To isolate the effects of market power, one would therefore have to control for the technological constraints and the effects of risk aversion on output and prices. 
Liberalized wholesale electricity markets actually consist of a collection of submarkets. Typically, generation companies can sell production up front at a day-ahead market, or they can take contractual positions in a forward market. But they can also reserve capacity to the delivery date and sell their production closer to real-time at various balancing markets. A theoretical contribution of this paper is to recognize that firms' multi-market presence can be used to control for unobservable covariates when evaluating market performance.

First, production and reservoir constraints do not matter for the trade-off between selling a given volume of production planned for day $t+1$ in the day-ahead market at day $t$ at price $f_{t+1}^{*}$ or saving it for the next day and selling it in real-time market at day $t+1$ at expected price $E_{t}\left[p_{t+1}^{*}\right]$. How to distribute a given amount of production across markets represents a portfolio selection problem, the solution to which is given by the consumption CAPM (Blanchard and Fischer, 1989). Hence, the expected marginal revenue in the real-time market equals the marginal revenue in the day-ahead market at equilibrium, corrected for the covariance between consumption and marginal revenue in the real-time market. In a competitive market, a (weakly) risk-averse producer must on average receive a (weakly) higher price in the real-time market than the day-ahead market, $E_{t}\left[p_{t+1}^{*}\right] \geq f_{t+1}^{*}$, to be willing to postpone sales until the next day. A negative relationship would be inconsistent with perfect competition.

Second, the marginal value to a hydro power producer of withholding production from the real-time market at day $t$ and releasing it on the real-time market at day $t+1$ depends on similar factors as the value of withholding sales from the day-ahead market at $t$ and selling it on the real-time market at $t+1$ instead. In the theoretical model, therefore, any difference between the real-time price $p_{t}^{*}$ at $t$ and the day-ahead price $f_{t+1}^{*}$ at $t$ for delivery at $t+1$ can be attributed either to production/reservoir constraints or to market power. Real-time prices and day-ahead prices are both risk-adjusted, so any risk correction cancels out. To isolate market power, it remains to control for the technological constraints. Although these constraints are measured in terms of shadow prices and therefore are difficult to estimate, it is considerably easier for an outsider to gauge whether they are likely to become more or less severe from one day to the next. Electricity demand varies predictably across time. For example, consumption is systematically higher on Mondays than Sundays. Tighter expected production constraints at day $t+1$ drive up $f_{t+1}^{*}$ relative to $p_{t}^{*}$ in a competitive market. Hence, competitiveness implies that production changes between $t$ and $t+1$ are positively related to the price difference $f_{t+1}^{*}-p_{t}^{*}$. A negative correlation would be a sign of imperfect competition. 
We apply these theoretical results to evaluate market performance at the Nordic power exchange, Nord Pool Spot (NPS), for the period 2010 through 2013 for the Swedish price area(s). The bulk of electricity production in the Nordic market is sold on NPS' day-ahead market, Elspot. Producers, retailers and large industrial consumers can then rebalance their positions on NPS' intraday market, Elbas, which we treat as our real-time market. Elbas opens two hours after the day-ahead market has closed and remains open until one hour prior to delivery. ${ }^{1}$

We match individual trade data from the real-time market (Elbas) to the hourly equilibrium auction prices established on the day-ahead market (Elspot). The conditional average real-time price was above the day-ahead price Mondays to Saturdays, but this relationship was reversed on Sundays. Hence, the observed price relations seem inconsistent with competitive prices. To control for the possibility of risk aversion on the demand side driving the results, we make use of an exogenous policy change during the sample period. On November 1, 2011 Sweden went from being a single price area in the day-ahead market to be partitioned into 4 price areas. By design, nearly all the hydropower is located in the two northern price areas, whereas all the nuclear power and most of the remaining thermal power generation is located in the two southern price areas. Owing to the flexible production in the north and the inflexible production in the south, rebalancing in the real-time market should primarily be done by producers in the north and large consumers in the south. If differences in risk aversion between producers and consumers was important, one would expect positive price differences in the northern price areas and negative price differences in the southern price areas. This is exactly what the data reveals. However, it is still the case that the price differences switch sign in the northern price areas on Sundays, and it also switches sign in the southern price areas on Fridays. Systematic differences in risk aversion between regions cannot explain why price differences switch sign within regions from one day to the next. We explore even alternative possibilities, such as marginal trading costs or thin real-time markets, but these are not plausible explanations for the large observed price differences. Overall, we reject the hypothesis that prices were at their competitive levels throughout the sample period.

The remainder of the paper is organized as follows. Section 2 discusses related literature. The theoretical model and its predictions are presented in Section 3. Section 4 contains the empirical analysis of the Nordic wholesale electricity market and interprets the findings. Section

\footnotetext{
${ }^{1}$ National balancing markets operated by the national transmission system operators (TSOs) subsequently take over. On top of the markets for physical delivery are the financial markets which allow market participants to hedge their production or consumption portfolios.
} 
5 concludes.

\section{Related literature}

Johnsen (2001), Førsund (2007) and Mathiesen et al. (2013) derive optimal hydro production under assumptions of perfect competition or monopoly, whereas Crampes and Moreaux (2001), Garcia et al. (2001) and Hansen (2009) analyse oligopolistic competition. Our theoretical model extends these previous contributions by incorporating a day-ahead market in addition to the real-time market into a hydro power model of imperfect competition. Multi-market presence allows to derive predictions of market performance based upon the comparison of equilibrium outcomes across markets.

Bessembinder and Lemmon (2002) build a theoretical model of forward contracting in a competitive electricity market. Allaz and Vila (1993), Hughes and Kao (1997), Mahenc and Salanié (2004) and Holmberg (2011) consider forward contracting in imperfectly competitive wholesale electricity markets. These forward contracting models are static and therefore do not capture the intertemporal dimension of hydro power markets. Generation companies in our setting are run so as to maximize expected utility of the decision maker. This specification allows to consider the effects of risk aversion on market outcomes, but also encompasses risk neutral preference and therefore profit maximization as a special case.

The empirical literature for the most part has approached the problem of unobservable marginal costs by means of structural estimation techniques. ${ }^{2}$ Wolak (2003) uses bid data at individual firm level from California whereas McRae and Wolak (2009) use similar bid data from New Zealand to estimate firm-specific residual demand elasticities. They show that prices are higher when residual demand is less elastic. These studies are exceptional insofar as individual bid data are hard to come by in many electricity markets, the Nordic market being one of them. To account for the lack of firm-level data, some have placed additional structure on the econometric model in terms of functional form assumptions (mostly linear-quadratic) for the demand and the marginal cost of producing electricity. These studies often are based on the well-known Bresnahan-Lau model; see Bask et al. (2011) or Graf and Wozabal (2013) for recent examples. But the Bresnahan-Lau model is essentially static and cannot easily be modified to

\footnotetext{
${ }^{2}$ It is less complicated to evaluate market performance in electricity markets which rely mainly on thermal energy because then reliable cost estimates based on engineering data for the individual power plants are readily available; see Wolfram (1999) and Borenstein et al. (2002) for classical applications to the UK and Californian electricity markets.
} 
capture the intertemporal aspects of hydro power markets. Indeed, estimation results turn out to be sensitive to model specification; see Kim and Knittel (2006) for a critical evaluation.

Another strand of the literature explicitly accounts for intertemporality by building dynamic numerical models of the electricity market. Examples of simulation models in this vein are Bushnell (2003), Kauppi and Liski (2008), and Philpott et al. (2010). Because of their computational burdens, simulation models often need to take an aggregate market view. The Kauppi and Liski (2008) model, for example, treats the Nordic region as a single integrated market and has a weekly resolution. At these high aggregation levels, it is not possible to identify any exercise of market power at the local level arising from bottlenecks and short-term demand variations.

The empirical approach suggested in this paper has minimal data requirements in the sense that it only uses equilibrium prices and quantities. It does not rely on estimation of demand and supply functions because predictions are derived directly from the first-order conditions for expected utility maximization. This also means it is possible to investigate market performance at the local market level. Borenstein et al. (2008) analyse day-ahead versus real-time price differences in the Californian electricity market. They argue that the observed price differences cannot plausibly be explained by risk aversion or transaction costs. ${ }^{3}$ A difference between their approach and ours is that we explicitly incorporate intertemporal substitution in the real-time market whereas Borenstein et al. (2008) assume this possibility away. Intertemporal substitution is a fundamental feature of wholesale electricity markets with substantial amounts of hydro power, such as the Nordic. Also, Borenstein et al. (2008) focus specifically on market power in the day-ahead market, we allow imperfect competition in both markets.

\section{Theoretical analysis}

\subsection{The model}

Technology Consider a power company with $N$ reservoir-based hydro power facilities. Hydro power plant $n \in \mathcal{N}=\{1, \ldots, N\}$ produces $q_{n t}$ MWh of energy day $t$ by a linear production function. All direct costs associated with hydro production are fixed in the short run, hence the marginal hydro production cost is zero. There is an upper bound $\bar{q}_{n t}$ stemming from limits to capacity. We allow the upper bound to vary as a function of time because scheduled and

\footnotetext{
${ }^{3}$ See Jha and Wolak (2014) for an empirical analysis of transaction costs in the Californian electricity market under the assumption of perfectly competitive markets. In the present context we can control directly for marginal transaction costs.
} 
unscheduled maintenance stops may cause capacity to fluctuate over time, so that real capacity $\bar{q}_{n t}$ sometimes is lower than nameplate capacity $\bar{q}_{n}$. Moreover, minimum flow requirements stemming from environmental constraints and seasonality might create a positive lower bound $\underline{q}_{n t} \geq 0$. Hence, at $t$ production satisfies

$$
q_{n t} \in\left[\underline{q}_{n t}, \bar{q}_{n t}\right] \text { for all } n \in \mathcal{N}
$$

Let $r_{n t}$ be the reservoir level in hydro plant $n$ at the end of day $t$ and denote by $i_{n t}$ reservoir inflow during $t$, both measured in MWh. Reservoir inflow is predictable, so we assume $i_{n t}$ to be known at the start of period $t$. The reservoir level in facility $n$ evolves according to

$$
r_{n t} \leq r_{n(t-1)}+i_{n t}-q_{n t}
$$

Write $\bar{r}_{n}$ the maximum reservoir capacity. Each hydro power plant also has a minimal reservoir level $\underline{r}_{n} \geq 0$, which may be strictly positive for environmental (or other) reasons. At $t$, reservoirs satisfy also

$$
r_{n t} \in\left[\underline{r}_{n}, \bar{r}_{n}\right] \text { for all } n \in \mathcal{N} \text {. }
$$

Firms are not allowed to spill water. Hence, we can write (1)-(3) as the merged reservoir constraints for all $n \in \mathcal{N}$ :

$$
\begin{aligned}
& r_{n t} \geq \underline{R}_{n}\left(r_{n(t-1)}\right)=\max \left\{\underline{r}_{n} ; r_{n(t-1)}+i_{n t}-\bar{q}_{n t}\right\}, \\
& r_{n t} \leq \bar{R}_{n}\left(r_{n(t-1)}\right)=\min \left\{\bar{r}_{n} ; r_{n(t-1)}+i_{n t}-\underline{q}_{n t}\right\} .
\end{aligned}
$$

At this point it is pertinent to discuss the assumption of linear hydro power technology. In day-to-day operations, water release is the only variable factor of production in a hydro power plant. Two factors affect the efficiency with which water is converted into electricity. First, as water is released from the dam, the height difference between the dam level and the turbine, the gross head, goes down. All else equal, a lower gross head implies lower production for given water release. For large reservoir power plants, day-to-day variations in release have negligible effects on the gross head, so this effect can safely be disregarded with the short time horizon considered here. Second, each turbine converts water into energy more or less efficiently depending on how much water is released through the turbine. Each turbine has an efficient operating span at which production increases linearly with water release. To achieve maximum efficiency over a wider 
production range, hydro power plants often have multiple turbines. Thus, a linear specification, as considered in most of the theoretical literature (e.g. Crampes and Moreaux, 2001; Garcia et al., 2001; Førsund, 2007; Hansen, 2009) as well as the simulation models (e.g. Bushnell, 2003; Kauppi and Liski, 2008; Philpott et al., 2010) seems a reasonable first approximation to normal day-to-day operations.

Markets The firm's aggregate production is $q_{t}=\sum_{n=1}^{N} q_{n t}$. Some of this, $z_{t-1}=\sum_{n=1}^{N} z_{n(t-1)}$, is sold in the the day-ahead market (at $t-1)$ for delivery the subsequent day (at $t$ ). Residual demand in the day-ahead market equals $f_{t}=F_{t}\left(z_{t-1}, \mathbf{r}_{t-1}\right)$ and is differentiable in all arguments. In general, residual demand depends also on the reservoir profile $\mathbf{r}_{t-1}=\left\{r_{n(t-1)}\right\}_{n=1}^{N}$. Rational competitors realize that $\mathbf{r}_{t-1}$ affects the future production decisions of the firm and adjust their own production accordingly. This adjustment affects residual demand; see Crampes and Moreaux (2001). The rest of total production, $x_{t}=\sum_{n=1}^{N} x_{n t}$, is sold in the real-time market, where the firm faces the differentiable residual inverse demand $p_{t}=P_{t}\left(x_{t}, z_{t-1}, \mathbf{r}_{t-1}\right)$.

In the Nordic market, producers are required to submit to the TSO a production plan detailing how they aim to cover their positions in the day-ahead market. This requirement implies that aggregate bids in the day-ahead market cannot exceed the maximal production capacity:

$$
0 \leq z_{t} \leq \bar{q}=\sum_{n=1}^{N} \bar{q}_{n}
$$

The decision maker of the firm enters $t$ with capital $k_{t-1}$ and consumes $c_{t}$, subject to the budget constraint

$$
c_{t}+k_{t} \leq p_{t} x_{t}+f_{t} z_{t-1}+k_{t-1} .
$$

For simplicity (this is innocuous), the risk-free interest rate between two periods is zero. All accounts pertaining to deliveries at $t$ are settled and consumption takes place simultaneously, at the end of day $t$.

The decision problem The decision maker maximizes the expected utility of consumption

$$
U\left(c_{t}\right)+\sum_{s=1}^{\infty} \beta^{s} E_{t}\left[U\left(c_{t+s}\right)\right]
$$

subject to the reservoir constraints (4), the bidding constraint (5), the budget constraint (6) and the transversality condition $\lim _{s \rightarrow \infty} k_{t+s}=0$. The subscript on the expectations operator 
indicates that the decision is taken with regards to the information available at $t$. In this model the producer simultaneously bids into the day-ahead market for delivery the subsequent day, $z_{t}$, and the real-time market for delivery today, $x_{t}$. With this timing, the day-ahead price for delivery the subsequent day, $f_{t+1}$, and today's real-time price, $p_{t}$, are determined simultaneously. The utility function $U(\cdot)$ is assumed to be continuously differentiable, strictly increasing in consumption, weakly concave and satisfy the Inada conditions. The period discount factor is $0<\beta<1$.

It is convenient to rewrite the maximization problem in terms of the problem of choosing a reservoir profile $\mathbf{r}_{t}$ for day $t$, how much to save for the subsequent day, $k_{t}$, and how much to commit to the subsequent day-ahead market, $z_{t}$. By virtue of the production relation

$$
x_{t}=\underbrace{\sum_{n=1}^{N}\left(r_{n(t-1)}+i_{n t}-r_{n t}\right)}_{q_{t}}-z_{t-1},
$$

we can rewrite profit as a function of $\mathbf{r}_{t}, z_{t-1}$ and $\mathbf{r}_{t-1}$ :

$$
\begin{aligned}
\pi_{t}\left(\mathbf{r}_{t}, z_{t-1}, \mathbf{r}_{t-1}\right)= & P(\underbrace{\sum_{n=1}^{N}\left(r_{n(t-1)}+i_{n t}-r_{n t}\right)-z_{t-1}}_{x_{t}}, z_{t-1}, \mathbf{r}_{t-1}) \times \\
& (\underbrace{\sum_{n=1}^{N}\left(r_{n(t-1)}+i_{n t}-r_{n t}\right)-z_{t-1}}_{x_{t}})+F_{t}\left(z_{t-1}, \mathbf{r}_{t-1}\right) z_{t-1} .
\end{aligned}
$$

Non-satiation of consumption implies that the budget constraint (6) is binding. Consequently, the Bellman equation becomes

$$
\begin{aligned}
v_{t}\left(z_{t-1}, \mathbf{r}_{t-1}, k_{t-1}\right) & =\max _{z_{t}, \mathbf{r}_{t}, k_{t}}\left\{U\left(\pi_{t}\left(\mathbf{r}_{t}, z_{t-1}, \mathbf{r}_{t-1}\right)+k_{t-1}-k_{t}\right)+\right. \\
& +\sum_{n=1}^{N}\left[\underline{\chi}_{n t}\left(r_{n t}-\underline{R}_{n}\left(r_{n(t-1)}\right)\right)+\bar{\chi}_{n t}\left(\bar{R}_{n}\left(r_{n(t-1)}\right)-r_{n t}\right)\right] \\
& \left.+\underline{\lambda}_{t} z_{t}+\bar{\lambda}_{t}\left(\bar{q}-z_{t}\right)+\beta E_{t}\left[v_{t+1}\left(z_{t}, \mathbf{r}_{t}, k_{t}\right)\right]\right\}
\end{aligned}
$$

where $\underline{\chi}_{n t} \geq 0$ and $\bar{\chi}_{n t} \geq 0$ are the Kuhn-Tucker multipliers associated with the reservoir constraints (4), while $\underline{\lambda}_{t}$ and $\bar{\lambda}_{t}$ are the Kuhn-Tucker multipliers associated with the bidding constraint (5).

All producer surplus is generated in the day-ahead and the real-time wholesale market in this model. Allowing vertical integration between the wholesale and retail market would not necessarily affect anything. To see this, let $z_{t}$ be the sum of day-ahead and retail supply. Assume that the integrated firm sells all of $z_{t}$ in the day-ahead market and then buys back its retail supply $y_{t}$ from the day-ahead market. The profit becomes $\pi_{t}=p_{t} x_{t}+f_{t} z_{t-1}+\left(r_{t}-f_{t}-\theta_{t}\right) y_{t-1}$, 
where $r_{t}$ is the retail price and $\theta_{t}$ the marginal retail cost. Owing to free entry, retail markets can be highly competitive, in which case $r_{t}-f_{t}=\theta_{t}$. In this case eq. (7) still characterizes profit, and the degree of vertical integration has no effect on wholesale competition. ${ }^{4}$

\subsection{Optimum}

Straightforward maximization with respect to the reservoir level in plant $n \in \mathcal{N}$ at date $t \geq 0$ yields the first-order condition (optimal values are indicated by asterisks)

$$
\begin{aligned}
& U^{\prime}\left(c_{t}^{*}\right) \frac{\partial \pi_{t}\left(\mathbf{r}_{t}^{*}, z_{t-1}, \mathbf{r}_{t-1}\right)}{\partial r_{n t}}+\underline{\chi}_{n t}^{*}-\bar{\chi}_{n t}^{*} \\
& \quad+\beta E_{t}\left[U^{\prime}\left(c_{t+1}^{*}\right) \frac{\partial \pi_{t+1}\left(\mathbf{r}_{t+1}^{*}, z_{t}^{*}, \mathbf{r}_{t}^{*}\right)}{\partial r_{n t}}\right]+E_{t}\left[\bar{\chi}_{n(t+1)}^{*} \bar{R}_{n}^{\prime}\left(r_{n t}^{*}\right)-\underline{\chi}_{n(t+1)}^{*} \underline{R}_{n}^{\prime}\left(r_{n t}^{*}\right)\right]=0 .
\end{aligned}
$$

To simplify notation, let $\partial P_{t+1}^{*} / \partial x_{t+1}=\partial P_{t+1}^{*}\left(x_{t+1}^{*}, z_{t}^{*}, \mathbf{r}_{t}^{*}\right) / \partial x_{t+1}$ and $\partial F_{t+1}^{*} / \partial r_{n t}=\partial F_{t+1}\left(z_{t}^{*}, \mathbf{r}_{t}^{*}\right) / \partial r_{n t}$.

Rewrite the first-order condition for the optimal reservoir level as (for all $n \in \mathcal{N}$ ):

$$
\begin{aligned}
p_{t}^{*}+\frac{\partial P_{t}^{*}}{\partial x_{t}} x_{t}^{*} & =\frac{\beta E_{t}\left[U^{\prime}\left(c_{t+1}^{*}\right)\right]}{U^{\prime}\left(c_{t}^{*}\right)} E_{t}\left[p_{t+1}^{*}+\left(\frac{\partial P_{t+1}^{*}}{\partial x_{t+1}}+\frac{\partial P_{t+1}^{*}}{\partial r_{n t}}\right) x_{t+1}^{*}+\frac{\partial F_{t+1}^{*}}{\partial r_{n t}} z_{t}^{*}\right] \\
& +\frac{\beta E_{t}\left[U^{\prime}\left(c_{t+1}^{*}\right)\right]}{U^{\prime}\left(c_{t}^{*}\right)} \frac{\operatorname{cov}_{t}\left[U^{\prime}\left(c_{t+1}^{*}\right), p_{t+1}^{*}+\left(\frac{\partial P_{t+1}^{*}}{\partial x_{t+1}}+\frac{\partial P_{t+1}^{*}}{\partial r_{n t}}\right) x_{t+1}^{*}\right]}{E_{t}\left[U^{\prime}\left(c_{t+1}^{*}\right)\right]} \\
& +\frac{\beta E_{t}\left[U^{\prime}\left(c_{t+1}^{*}\right)\right]}{U^{\prime}\left(c_{t}^{*}\right)} \frac{\underline{\chi}_{n t}^{*}-\bar{\chi}_{n t}^{*}-E_{t}\left[\underline{\chi}_{n(t+1)}^{*} \underline{R}_{n}^{\prime}\left(r_{n t}^{*}\right)-\bar{\chi}_{n(t+1)}^{*} \bar{R}_{n}^{\prime}\left(r_{n t}^{*}\right)\right]}{\beta E_{t}\left[U^{\prime}\left(c_{t+1}^{*}\right)\right]} .
\end{aligned}
$$

This optimality condition is a generalization of the celebrated Hotelling rule which in its most basic form states that the price of a natural resource evolves proportionally to the real interest rate of return, which in this model is equal to zero. Hence, the simplest version of the Hotelling rule predicts price stability. Here, the firm which extracts the resource (water) potentially exercises market power. Market power and uncertainty imply that the firm equates expected marginal revenue across time. The assumption that the decision maker maximizes expected utility instead of expected profit implies that future profit is discounted by the intertemporal marginal rate of substitution. This is the first line in eq. (8) above. Uncertainty and risk aversion imply that resource extraction is adjusted by a risk correction factor, the magnitude of which depends on the correlation between consumption and marginal revenue in the real-time market. Risk correction is the term in the second line above. Finally, resource extraction is

\footnotetext{
${ }^{4}$ This would seem at odds with the empirical findings by Bushnell et al. (2008) that vertical integration improves wholesale market performance. However, retail prices were more or less fixed in their sample, so that the pass-through of the wholesale price to the retail price was zero. The above result is derived under the assumption of full price flexibility and perfect competition in the retail market, which instead implies full pass-through.
} 
limited by production and/or reservoir constraints captured by the shadow prices in the final line of eq. (8).

Consider next optimal bidding in the day-ahead market. By way of the first-order condition

$$
\beta E_{t}\left[U^{\prime}\left(c_{t+1}^{*}\right) \partial \pi_{t+1}\left(\mathbf{r}_{t}^{*}, z_{t}^{*}, k_{t}^{*}\right) / \partial z_{t}\right]+\underline{\lambda}_{t}^{*}-\bar{\lambda}_{t}^{*}=0,
$$

the optimal contract position $z_{t}^{*}$ solves:

$$
\begin{aligned}
E_{t}\left[p_{t+1}^{*}+\left(\frac{\partial P_{t+1}^{*}}{\partial x_{t+1}}-\frac{\partial P_{t+1}^{*}}{\partial z_{t}}\right) x_{t+1}^{*}\right] & =f_{t+1}^{*}+\frac{\partial F_{t+1}^{*}}{\partial z_{t}} z_{t}^{*}-\frac{\operatorname{cov}_{t}\left[U^{\prime}\left(c_{t+1}^{*}\right), p_{t+1}^{*}+\left(\frac{\partial P_{t+1}^{*}}{\partial x_{t+1}}-\frac{\partial P_{t+1}^{*}}{\partial z_{t}}\right) x_{t+1}^{*}\right]}{E_{t}\left[U^{\prime}\left(c_{t+1}^{*}\right)\right]} \\
& +\frac{\lambda_{t}^{*}-\bar{\lambda}_{t}^{*}}{\beta E_{t}\left[U^{\prime}\left(c_{t+1}^{*}\right)\right]} .
\end{aligned}
$$

For any planned production level $q_{t+1}$ the subsequent period, the producer has the choice between allocating some of it, $z_{t}$, to the day-ahead market and saving the rest, $x_{t+1}$, for the real-time market. This decision is equivalent to a portfolio selection problem in which a share of wealth is invested up front with known return (the day-ahead market) and the rest in an asset with risky future return (the real-time market). Owing to expected utility maximization, the optimum is a variant of the consumption CAPM (Blanchard and Fischer, 1989), taking into account the possibility of market power and bidding restrictions in the day-ahead market: Expected marginal revenue in the real-time market equals marginal revenue in the day-ahead market, corrected by a risk-aversion factor which depends on the correlation between consumption and marginal revenue in the real-time market. Marginal revenue in the day-ahead market is deterministic here. In most deregulated electricity markets, producers bid in supply functions. Supply functions generally allow producers ex ante to optimally adapt production to every ex post realization of demand. It is as if demand were, indeed, deterministic; see e.g. Klemperer and Meyer (1989), Wolak (2003) and Holmberg (2008).

Finally, the first-order condition for the optimal savings decision gives the intertemporal marginal rate of substitution: ${ }^{5}$

$$
\frac{\beta E_{t}\left[U^{\prime}\left(c_{t+1}^{*}\right)\right]}{U^{\prime}\left(c_{t}^{*}\right)}=1
$$

\subsection{Theoretical predictions}

Using (8) and (10) we obtain:

\footnotetext{
${ }^{5}$ Optimal saving is why interest rates do not matter with the chosen time horizon. In general, optimal saving is equivalent to $\beta E_{t}\left[U^{\prime}\left(c_{t+1}^{*}\right)\right] / U^{\prime}\left(c_{t}^{*}\right)=\left(1+r_{t}\right)^{-1} \approx 1$, where $r_{t}$ is the (infinitesimal) risk-free interest rate between $t$ and $t+1$.
} 
Proposition 1. The equilibrium real-time price evolves according to

$$
\begin{aligned}
p_{t+1}^{*}-p_{t}^{*} & =\frac{\partial P_{t}^{*}}{\partial x_{t}} x_{t}^{*}-E_{t}\left[\left(\frac{\partial P_{t+1}^{*}}{\partial x_{t+1}}+\frac{\partial P_{t+1}^{*}}{\partial r_{n t}}\right) x_{t+1}^{*}\right]-\frac{\partial F_{t+1}^{*}}{\partial r_{n t}} z_{t}^{*}-\frac{\operatorname{cov}_{t}\left[U^{\prime}\left(c_{t+1}^{*}\right),\left(\frac{\partial P_{t+1}^{*}}{\partial x_{t+1}}+\frac{\partial P_{t+1}^{*}}{\partial r_{n t}}\right) x_{t+1}^{*}\right]}{E_{t}\left[U^{\prime}\left(c_{t+1}^{*}\right)\right]} \\
& +\frac{\bar{\chi}_{n t}^{*}-\underline{\chi}_{n t}^{*}+E_{t}\left[\underline{\chi}_{n(t+1)}^{*} \underline{R}_{n}^{\prime}\left(r_{n t}^{*}\right)\right]-E_{t}\left[\bar{\chi}_{n(t+1)}^{*} \bar{R}_{n}^{\prime}\left(r_{n t}^{*}\right)\right]}{\beta E_{t}\left[U^{\prime}\left(c_{t+1}^{*}\right)\right]}-\frac{\operatorname{cov}_{t}\left[U^{\prime}\left(c_{t+1}^{*}\right), p_{t+1}^{*}\right]}{E_{t}\left[U^{\prime}\left(c_{t+1}^{*}\right)\right]}+p_{t+1}^{*}-E_{t}\left[p_{t+1}^{*}\right] .
\end{aligned}
$$

Price fluctuations in the real-time market have four potential explanations in this model: (i) the exercise of market power - the sum of the terms on the first line of (11); (ii) binding production and/or reservoir constraints - the first term on the second line of (11); (iii) risk aversion - the second term on the second line of $(11)$; (iv) surprise events causing price shocks - the final term on the second line above. Under the assumption that price shocks are random with zero mean, one would still have to control for the technological constraints and the effects of risk aversion on prices to isolate the effects of market power in the real-time market. We now demonstrate that each of these effects can be controlled for separately by manipulating the optimality conditions.

Rewriting (9) yields:

Proposition 2. The equilibrium relation between the real-time price $p_{t+1}^{*}$ and the day-ahead price $f_{t+1}^{*}$ for delivery the same day $(t+1)$ equals

$$
\begin{aligned}
p_{t+1}^{*}-f_{t+1}^{*} & =\frac{\partial F_{t+1}^{*}}{\partial z_{t}} z_{t}^{*}+E_{t}\left[\left(\frac{\partial P_{t+1}^{*}}{\partial z_{t}}-\frac{\partial P_{t+1}^{*}}{\partial x_{t+1}}\right) x_{t+1}^{*}\right]+\frac{\operatorname{cov}_{t}\left[U^{\prime}\left(c_{t+1}^{*}\right),\left(\frac{\partial P_{t+1}^{*}}{\partial z_{t}}-\frac{\partial P_{t+1}^{*}}{\partial x_{t+1}}\right) x_{t+1}^{*}\right]}{E_{t}\left[U^{\prime}\left(c_{t+1}^{*}\right)\right]} \\
& -\frac{\operatorname{cov}_{t}\left[U^{\prime}\left(c_{t+1}^{*}\right), p_{t+1}^{*}\right]}{E_{t}\left[U^{\prime}\left(c_{t+1}^{*}\right)\right]}+\frac{\lambda_{t}^{*}-\bar{\lambda}_{t}^{*}}{\beta E_{t}\left[U^{\prime}\left(c_{t+1}^{*}\right)\right]}+p_{t+1}^{*}-E_{t}\left[p_{t+1}^{*}\right] .
\end{aligned}
$$

The production and reservoir constraints have disappeared compared with (11) because they do not affect the choice of market, day-ahead or real-time, on which to sell the planned production.

When estimating (12), one should first control for observable demand and supply shocks that are realized after gate closure of the day-ahead market, but prior to the determination of the real-time price. Typical shocks include production or transmission failures and unexpected temperature changes. In view of (12), remaining systematic price differences would be due to market power, risk aversion or bidding constraints in the day-ahead market.

The incentive to exercise market power varies predictably across time with fluctuations in the price elasticity of demand and as transmission constraints become more or less severe. Hence, one should control for seasonal variation when estimating (12). However, factors which would 
affect the incentive to exercise market power may also affect prices under perfect competition. For example, transmission constraints increase local market concentration and could therefore be associated with local market power. However, bottlenecks are also likely to increase price volatility in the real-time market because it is then less probable that positive local shocks are offset by negative shocks in neighbouring markets. Hence, market power and risk aversion may go hand in hand and could be difficult to separate from one another by means of exogenous controls.

One would usually expect a firm both to participate at the day-ahead market and to reserve some capacity for future eventualities $\left(0<z_{t}^{*}<\bar{q}\right)$ so that $\underline{\lambda}_{t}^{*}=\bar{\lambda}_{t}^{*}=0$. If markets are also competitive, then all terms on the first line of (12) vanish, so all remaining differences between the expected real-time price and the day-ahead price would be due to risk aversion:

$$
E_{t}\left[p_{t+1}^{*}\right]-f_{t+1}^{*}=-\frac{\operatorname{cov}_{t}\left[U^{\prime}\left(c_{t+1}^{*}\right), p_{t+1}^{*}\right]}{E_{t}\left[U^{\prime}\left(c_{t+1}^{*}\right)\right]} .
$$

A negative demand shock which decreases the equilibrium price, $p_{t+1}^{*}$, would also decrease firm profit, $\pi_{t+1}^{*}=p_{t+1}^{*} x_{t+1}^{*}+f_{t+1}^{*} z_{t}^{*}$, and therefore consumption, $c_{t+1}^{*}$. Demand shocks thus imply a (weakly) negative covariance of $p_{t+1}^{*}$ and $U^{\prime}\left(c_{t+1}^{*}\right)$. A negative supply shock, such as a production failure, would decrease profit $\pi_{t+1}^{*}$ and consumption $c_{t+1}^{*}$, but have no effect on the anticipated equilibrium price $p_{t+1}^{*}$ under perfect competition. Under perfect competition, therefore, $\operatorname{cov}_{t}\left[U^{\prime}\left(c_{t+1}^{*}\right), p_{t+1}^{*}\right]<0$ if the decision maker is risk averse and zero if she is risk neutral. Hence, we obtain our first competitive hypothesis:

Hypothesis 1. If the market is competitive, then $E_{t}\left[p_{t+1}^{*}\right] \geq f_{t+1}^{*}$.

This hypothesis states that in a competitive market a risk-averse producer on average must receive a higher price in the real-time market than the day-ahead market to be willing to take the risk of postponing sales until the next day.

By assumption only the producers care about risk in this model. If instead the buyers were more risk averse than the producers, they would pay a risk premium to be able to advance purchases to the day-ahead market. In this case, even $E_{t}\left[p_{t+1}^{*}\right]<f_{t+1}^{*}$ could be consistent with competitive pricing. However, it is the TSO that constitutes the contractual counterpart to the producers in the real-time market. By market design, the TSO is prohibited from buying and selling electricity in the day-ahead market, and consequently has no possibility for hedging real-time contract positions. In a real-time market mainly populated by producers and the TSO 
only seller risk aversion will affect price differences between the real-time and the day-ahead market. Still, the sign of the risk premium becomes important in our empirical analysis, so we revisit this issue below.

The main problem with estimating (12) is that the degree of risk aversion is unobservable. To control for risk aversion, subtract (12) from (11) and rearrange:

Proposition 3. The equilibrium relation between the real-time price $p_{t}^{*}$ and the day-ahead price $f_{t+1}^{*}$, both determined at the same time (t) is:

$$
\begin{aligned}
f_{t+1}^{*}-p_{t}^{*} & =\frac{\partial P_{t}^{*}}{\partial x_{t}} x_{t}^{*}-E_{t}\left[\left(\frac{\partial P_{t+1}^{*}}{\partial z_{t}}+\frac{\partial P_{t+1}^{*}}{\partial r_{n t}}\right) x_{t+1}^{*}\right]-\left(\frac{\partial F_{t+1}^{*}}{\partial z_{t}}+\frac{\partial F_{t+1}^{*}}{\partial r_{n t}}\right) z_{t}^{*}-\frac{\operatorname{cov}_{t}\left[U^{\prime}\left(c_{t+1}^{*}\right),\left(\frac{\partial P_{t+1}^{*}}{\partial z_{t}}+\frac{\partial P_{t+1}^{*}}{\partial r_{n t}}\right) x_{t+1}^{*}\right]}{E_{t}\left[U^{\prime}\left(c_{t+1}^{*}\right)\right]} \\
& +\frac{\bar{\chi}_{n t}^{*}-\underline{\chi}_{n t}^{*}+E_{t}\left[\underline{\chi}_{n(t+1)}^{*} \underline{R}_{n}^{\prime}\left(r_{n t}^{*}\right)\right]-E_{t}\left[\bar{\chi}_{n(t+1)}^{*} \bar{R}_{n}^{\prime}\left(r_{n t}^{*}\right)\right]+\underline{\lambda}_{t}^{*}-\bar{\lambda}_{t}^{*}}{\beta E_{t}\left[U^{\prime}\left(c_{t+1}^{*}\right)\right]} .
\end{aligned}
$$

Once we have appropriately controlled for current and expected production, reservoir and bidding constraints, any remaining price differences are necessarily due to the exercise of market power. This relation holds independently of the decision maker's attitude towards risk. Risk adjustment vanishes here because trading in the real-time market the following period represents the opportunity cost both of $f_{t+1}^{*}$ and $p_{t}^{*}$.

One would control for seasonal variation also when estimating (14), as market power presumably would vary across time with demand fluctuations and transmission bottlenecks. However, the price shocks in the real-time market have vanished because $f_{t+1}^{*}$ and $p_{t}^{*}$ are simultaneously determined (at $t$ ). Hence, demand and supply shocks realized subsequent to period $t$ should have no significant effect on the price differences.

The main problem with estimating (14) lies in the fact that the shadow prices on the constraints are unobservable to outside observers and probably also correlated with the incentives to exercise market power. But the equilibrium price relation actually depends on the difference between the current and expected shadow prices. While the level of the shadow prices is difficult to estimate, it could be easier to predict how they change over time.

Let the current aggregate production be $Q_{t}^{*}$, and suppose that producers are uncertain abut future supply, but convinced that it will be higher the subsequent period than today: $Q_{t+1}^{*}>$ $Q_{t}^{*}$. Higher production means that $q_{n(t+1)}^{*}>q_{n t}^{*}$ for one or more plants $n \in \mathcal{N}$. Assume that at least one of these plants is fully operational at $t$, so that $\bar{q}_{n t} \geq \bar{q}_{n(t+1)}$. Collecting inequalities yields

$$
\bar{q}_{n t} \geq \bar{q}_{n(t+1)} \geq q_{n(t+1)}^{*}>q_{n t}^{*} \geq \underline{q}_{n t},
$$


hence $r_{n t}^{*}>r_{n(t-1)}^{*}+i_{n t}-\bar{q}_{n t}$ and $r_{n(t+1)}^{*}<r_{n t}^{*}+i_{n(t+1)}-\underline{q}_{n t}$. Assume also that current reservoir conditions are interior, i.e. $r_{n t}^{*} \in\left(\underline{r}_{n}, \bar{r}_{n}\right)$. In this case, $r_{n t}^{*}>\underline{R}_{n}\left(r_{n(t-1)}^{*}\right)$ so that $\underline{\chi}_{n t}^{*}=0$. If reservoir inflow is small so that $r_{n t}^{*}+i_{n(t+1)}-\underline{q}_{n t} \leq \bar{r}_{n}$, then $r_{n(t+1)}^{*}<\bar{R}\left(r_{n t}^{*}\right)$ and $\bar{\chi}_{n(t+1)}^{*}=0$, but if reservoir inflow is large so that $r_{n t}^{*}+i_{n(t+1)}-\underline{q}_{n t}>\bar{r}_{n}$, then $\bar{R}^{\prime}\left(r_{n t}^{*}\right)=0$; see eq. (4). Assume finally, that the producers reserve some capacity for the real-time market so that $\bar{\lambda}_{t}^{*}=0$. In this case,

$$
\frac{\bar{\chi}_{n t}^{*}-\underline{\chi}_{n t}^{*}+E_{t}\left[\underline{\chi}_{n(t+1)}^{*} \underline{R}_{n}^{\prime}\left(r_{n t}^{*}\right)\right]-E_{t}\left[\bar{\chi}_{n(t+1)}^{*} \bar{R}_{n}^{\prime}\left(r_{n t}^{*}\right)\right]+\underline{\lambda}_{t}^{*}-\bar{\lambda}_{t}^{*}}{\beta E_{t}\left[U^{\prime}\left(c_{t+1}^{*}\right)\right]}=\frac{\bar{\chi}_{n t}^{*}+E_{t}\left[\underline{\chi}_{n(t+1)}^{*} \underline{R}_{n}^{\prime}\left(r_{n t}^{*}\right)\right]+\underline{\lambda}_{t}^{*}}{\beta E_{t}\left[U^{\prime}\left(c_{t+1}^{*}\right)\right]} \geq 0
$$

In the opposite case of producers ascertaining $Q_{t+1}^{*}<Q_{t}^{*}$ :

$$
\frac{\bar{\chi}_{n t}^{*}-\underline{\chi}_{n t}^{*}+E_{t}\left[\underline{\chi}_{n(t+1)}^{*} \underline{R}_{n}^{\prime}\left(r_{n t}^{*}\right)\right]-E_{t}\left[\bar{\chi}_{n(t+1)}^{*} \bar{R}_{n}^{\prime}\left(r_{n t}^{*}\right)\right]+\underline{\lambda}_{t}^{*}-\bar{\lambda}_{t}^{*}}{\beta E_{t}\left[U^{\prime}\left(c_{t+1}^{*}\right)\right]}=-\frac{\underline{\chi}_{n t}^{*}+E_{t}\left[\bar{\chi}_{n(t+1)}^{*} \bar{R}_{n}^{\prime}\left(r_{n t}^{*}\right)\right]+\bar{\lambda}_{t}^{*}}{\beta E_{t}\left[U^{\prime}\left(c_{t+1}^{*}\right)\right]} \leq 0
$$

for some facility $n \in \mathcal{N}$ under normal production conditions $\left(\bar{q}_{n(t+1)}=\bar{q}_{n t} \geq q_{n t}^{*}>q_{n(t+1)}^{*} \geq\right.$ $\left.\underline{q}_{n t}\right)$, interior reservoir conditions $\left(r_{n t}^{*} \in\left(\underline{r}_{n}, \bar{r}_{n}\right)\right)$ and interior bidding conditions $\left(\underline{\lambda}_{t}^{*}=0\right)$.

The two above inequalities yield

$$
\left(Q_{t+1}^{*}-Q_{t}^{*}\right)\left(f_{t+1}^{*}-p_{t}^{*}\right)=\left(Q_{t+1}^{*}-Q_{t}^{*}\right) \frac{\bar{\chi}_{n t}^{*}-\underline{\chi}_{n t}^{*}+E_{t}\left[\underline{\chi}_{n(t+1)}^{*} \underline{R}_{n}^{\prime}\left(r_{n t}^{*}\right)\right]-E_{t}\left[\bar{\chi}_{n(t+1)}^{*} \bar{R}_{n}^{\prime}\left(r_{n t}^{*}\right)\right]}{E_{t}\left[U^{\prime}\left(c_{t+1}^{*}\right)\right]} \geq 0
$$

at competitive equilibrium whenever the direction of the aggregate supply change is perfectly predictable from one period to the next. Taking expectations delivers our second competitive hypothesis:

Hypothesis 2. If the market is competitive, then $\left(E_{t}\left[Q_{t+1}^{*}\right]-Q_{t}^{*}\right)\left(f_{t+1}^{*}-p_{t}^{*}\right) \geq 0$.

This hypothesis states that the day-ahead price tends to be higher (lower) than the current real-time price at competitive equilibrium if production is predicted to increase (fall) the subsequent period. It corresponds to a peak-load pricing prediction applied to the day-ahead and real-time market.

\section{Empirical analysis of the Nordic wholesale electricity market}

\subsection{Market description}

The Nordic countries rely heavily on hydro power for electricity supply; see Table 1. Half of the installed generation capacity is hydro power, predominantly located in Norway and Sweden. 


\begin{tabular}{lccccc} 
& Denmark & Finland & Norway & Sweden & Total \\
\hline Hydro & 0 & 3.2 & 30.7 & 16.2 & 50.1 \\
Nuclear & 0 & 2.7 & 0 & 9.4 & 12.1 \\
Other thermal & 9.8 & 11.1 & 1.1 & 8.0 & 30.0 \\
Wind & 4.2 & 0.3 & 0.7 & 3.7 & 8.9 \\
Total & 14.0 & 17.3 & 32.5 & 37.3 & 101.1
\end{tabular}

Table 1: Generation capacity (GWe) in 2012 (Source: NordREG, 2013)

Remaining generation capacity is for the most part Finnish and Swedish nuclear power and other thermal power - mainly combined heat and power and condensing power - in Denmark, Finland and Sweden. Wind power is a growing source of generation and is located primarily in Denmark and Sweden.

Market concentration is fairly low on an aggregate level. There are five large producers, the largest of which, Vattenfall, owns roughly 16 per cent of installed production capacity (NordREG, 2013). However, aggregate numbers do not give the full picture of market concentration. Transmission bottlenecks on international connections often split the Nordic market into a subset of national markets; see more on this below. Four of the five largest producers are former national monopolies (the exception is E.ON) with generation assets concentrated to the home market. Hence, national market concentration is higher than what the aggregate numbers would seem to suggest. As an illustrative case in point, Vattenfall owns 37 per cent of Swedish generation capacity (NordREG, 2013). Joint ownership is widespread and creates collective market concentration. All Swedish nuclear power, for example, is jointly owned by the three large producers Vattenfall, Fortum and E.ON. Owing to local market concentration and joint ownership, there is reason to be concerned about market performance in the Nordic wholesale electricity market.

The cornerstone of the market is the power exchange, Nord Pool Spot (NPS). ${ }^{6}$ In 2012, NPS traded 337.2 TWh electricity, which amounts to 77 per cent of total consumption in the Nordic countries that year. ${ }^{7}$ NPS operates two main markets, the most important of which is the dayahead market, Elspot. Elspot handled 99 per cent (334 TWh) of the traded volume on NPS in 2012. The remaining 3.2 TWh were traded on the intraday market, Elbas, which we refer

\footnotetext{
${ }^{6}$ NPS traces its origin back to 1991 when Norway established a trading system for wholesale electricity as part of liberalizing its electricity sector. Sweden, Finland and Denmark subsequently joined to create what was then the first multinational power exchange in the world. NPS has later integrated with Continental Europe and the Baltic countries.

${ }^{7}$ The rest of consumption stems from bilateral contracts between producers and industrial consumers or represents direct deliveries internal to vertically integrated producers and retailers.
} 
to as the real-time market. ${ }^{8}$ The day-ahead market is divided into a number of smaller price areas, or zones, to account for international and domestic transmission bottlenecks. There are two price areas in Denmark and five in Norway, whereas Finland, Estonia, Latvia and Lithuania each constitute a separate price area for the time being. Sweden was a single price area until October 31, 2011, subsequent to which the country was split into four price areas. The Swedish price area reform was introduced to comply with demands by the EU competition authority to improve how Sweden handled internal supply and demand imbalances.

We apply the methodology developed in the previous section to test for market power on NPS in the Swedish price area(s). We examine the period January 1, 2010 until December 31, 2013. Because generation in Sweden is geographically separated, with nearly all the hydropower located in the north while most of the nuclear and other thermal generation is located in the south, we use the introduction of new price areas to compare results of the empirical test between hydropower dominated and thermal dominated areas.

\subsection{The data}

The day-ahead market - Elspot Participation in the day-ahead market is voluntary, but only producers with local generation capacity, local industrial consumers and retailers who serve local end users are allowed to trade electricity there. Market participants submit hourly demand or supply curves for physical delivery over the next day's 24-hour period. Bidding for the 24 periods of day $t+1$ commences at noon, day $t-1$ and closes at noon, day $t$. Only the final bid curves prior to gate closure are binding. NPS aggregates the individual supply and demand bids and clears the market by means of a uniform price for each hour and price area, taking into account the transmission constraints. The system price is the hourly clearing price for the entire market and would constitute the equilibrium price absent any transmission constraints. But as bottlenecks are frequent, it makes sense to conduct the empirical analysis at price area level. Hence, the day-ahead market is best described as a collection of regional markets (price areas) with inter-regional trade limited by the capacity of the transmission lines.

In summary, $f_{h, t}^{*}$, corresponds to the average hourly day-ahead (Elspot) price in the relevant Swedish price area for delivery hour $h$ of day $t$. This corresponds to 110,000 observations between January 1, 2010 and December 31, 2013. The prices we use are in Euro per Megawatt-hour (EUR/MWh). Day-ahead prices can be downloaded from the website of NPS

\footnotetext{
${ }^{8}$ All numbers are from the NPS Annual Report 2013 which can be accessed at www.nordpoolspot.com.
} 
(www.nordpoolspot.com).

The real-time market - Elbas This market opens two hours after gate closure of the dayahead market and closes one hour prior to physical delivery. Elbas resembles a regular stock market in the sense that trading is continuous. Continuous trading implies that the same product typically is traded at multiple prices over the course of the trading period as new market information arrives. In our regressions we use data on settled prices of individual trades. $p_{i, h, t}^{*}$ then represents the accepted price of trade $i$ for delivery in a certain hour $h$ at day $t$. We include only trades that are made between 8 and $12^{9}$ in the morning, so that the information set of the Elbas trades is as comparable as possible with the information set upon which the day-ahead prices are based (submitted at 12 noon). We are then left with approximately 22,000 trades between January 1, 2010 and December 31, 2013 where the seller is located in Sweden. Elbas trades and clearing prices are available upon request from NPS.

Additional variables $E_{t-1}\left[Q_{h, t}^{*}\right]$ is the expected production at hour $h$ in day $t$ in the relevant Swedish price area as per the previous day, while $Q_{h, t}^{*}$ is the actual production. Expected and realized production data are available as of July 1, 2010 from the Swedish TSO, Svenska Kraftnät's, website (www.svk.se). As Figure 1 shows, average realized production in Sweden is markedly lower on the weekends, corresponding to weekly consumption patterns. ${ }^{10}$

Nord Pool Spot also has a system for reporting failures in the electricity system called Urgent Market Messages (UMMs). In the regressions, we include a measure of UMMs indicating failures from coal, hydro or nuclear plants of at least 100 MWe. In particular, we include dummy variables that represent unscheduled failures that become known after gate closure of the dayahead market for any given day, thus they represent events that affect supply and potentially prices on the real-time market, but not the day-ahead market. We also assume that these failures are random events. As Figure 2 shows, the vast majority of days are free from major plant outages, although multiple outages in a day are still common, especially for coal and hydro plants.

Finally, we also include measures of daily temperature differences in the four regions of Sweden that correspond to the four price areas, labeled SE1-SE4. Daily temperature differences as calculated by changes in heating degree days are included for Luleå in the northernmost

\footnotetext{
${ }^{9}$ This is not the time of delivery - but rather the time the trade actually happens on the market.

${ }^{10}$ Calculations and statistical analysis are done using the $\mathrm{R}$ statistical programming language ( $\mathrm{R}$ Core Team, 2013). All figures are drawn using the R package ggplot2 (Wickham, 2009).
} 


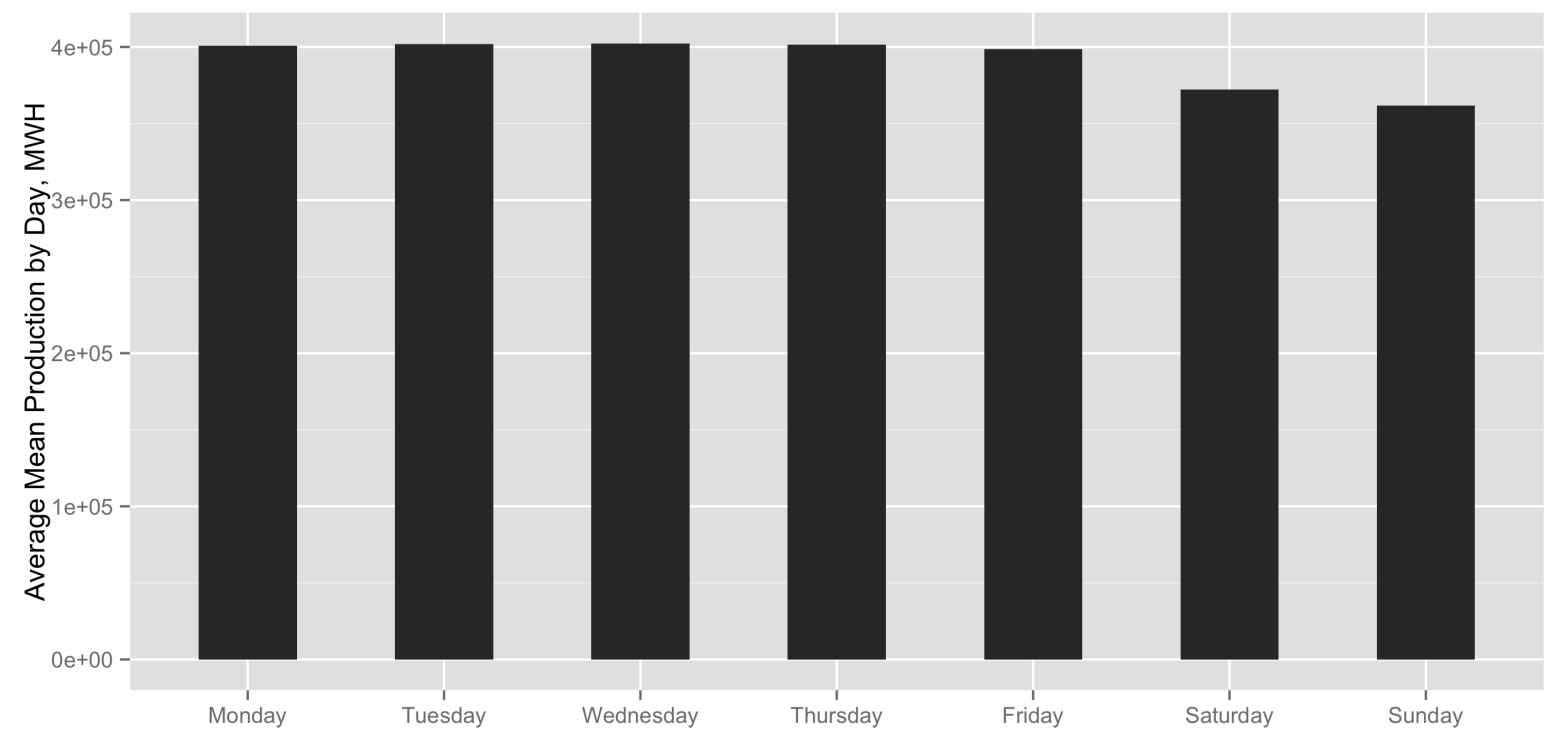

Figure 1: Daily production averages. Production tends to be lower on Saturday and Sunday.

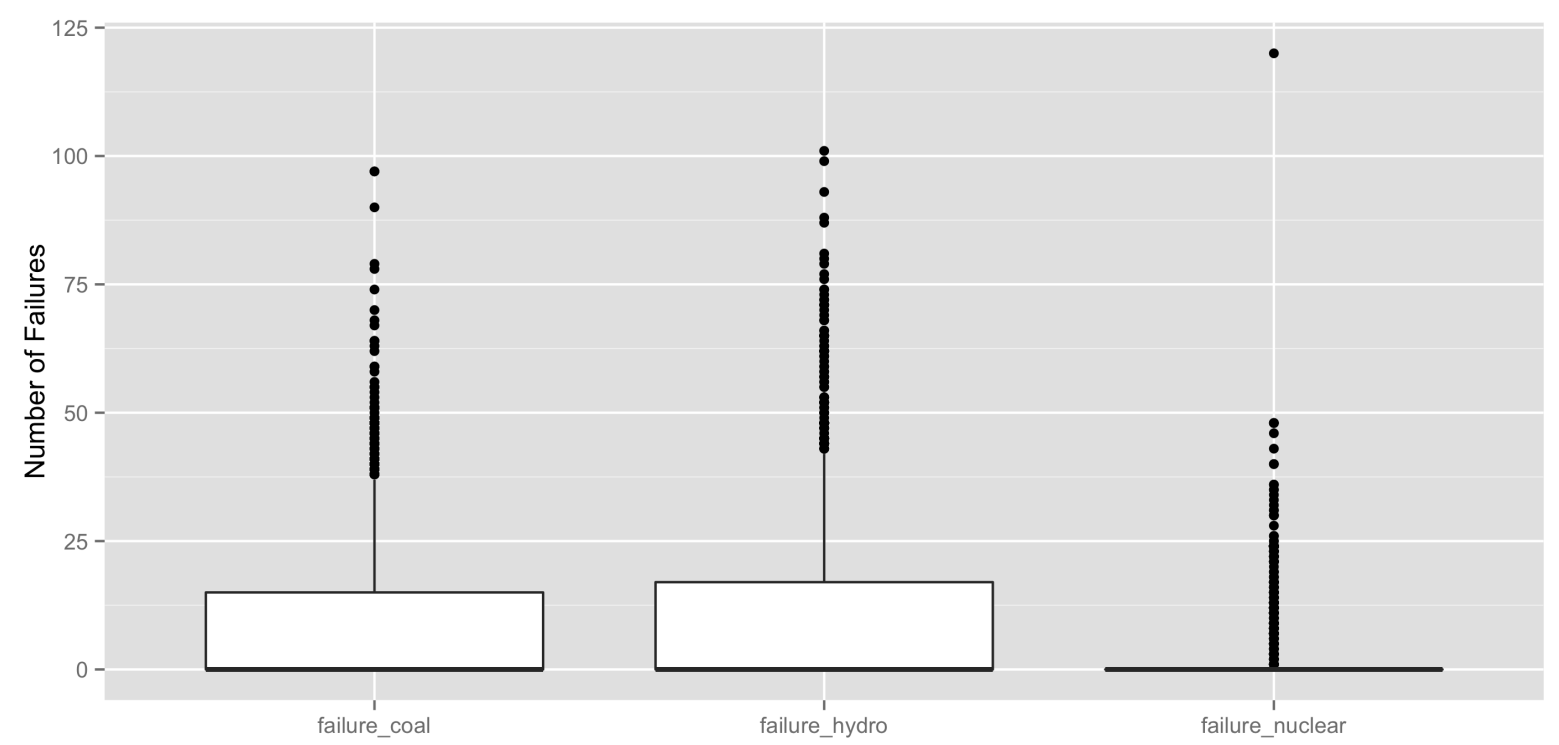

Figure 2: Frequency of unexpected power plant failures as reported in Urgent Market Messages (UMM) 
price area (SE1), Sundsvall further down (SE2), Stockholm in the middle price area (SE3) and Malmö in the southernmost price area (SE4). Heating degree days (HDD) are calculated in centigrade-day units where temperatures were below some base temperature defined as where a building does not require any heating. In the data we use, this is set at 15.5 degrees Celsius. For example, if the temperature was at 10 degrees for 24 hours, this would be recorded as 5.5 HDD. However, the level of the base temperature does not matter when we use daily differences in HDD.

\subsection{Results}

Hypothesis 1 On average, the real-time price should be higher than the day-ahead price in a competitive market. To test this hypothesis, we match prices on the day-ahead market (Elspot) with prices on the real-time market (Elbas) where delivery is on the same hour. Figure 3 shows this difference between the real-time price and the day-ahead price per trade, $i$, on the real-time market. The first panel depicts the price differences up until October 31, 2011 when Sweden was one price area, labeled SE. The four subsequent panels illustrate the respective price differences in the four price areas SE1-SE4 from November 1, 2011 until December 31, 2013.

All of the series appear to be centered around zero with occasional large deviations, although these tend to quickly revert to the mean. This can also be seen in the form of histograms in Figure 4. In SE and SE 1, price differences appear to be skewed upwards, whereas the opposite is case for the other price areas SE2-SE4. Large price fluctuations are pervasive to wholesale electricity markets and could reflect a momentary exercise of market power. However, the single exceptionally large deviation seen in early 2010 in the first panel has the potential to heavily influence the results of the regression with just a single trade. Thus this data point is removed from the data set to get results that reflect a generalized state of the market. Unsurprisingly, the series can be shown to be stationary. However, the variance of the series appears to vary over time and the series can also be shown to be autocorrelated.

We run a regression represented by equation (15) where the difference between the price of a real-time trade (Elbas), $i$, for delivery hour $h$ of day $t, p_{i, h, t}^{*}$, and the day-ahead price (Elspot) for delivery hour $h$ of day $t$ (determined at day $t-1$ ), $f_{h, t}^{*}$, is our dependent variable. On the right hand side, we include a vector of dummy variables, $\boldsymbol{Y}_{t}$, that represents whether the trade took place before or after the price area reform, and if after the reform, whether it was in one of the southern price areas (SE-S) or two northern (SE-N) price areas. As no separate intercept term 

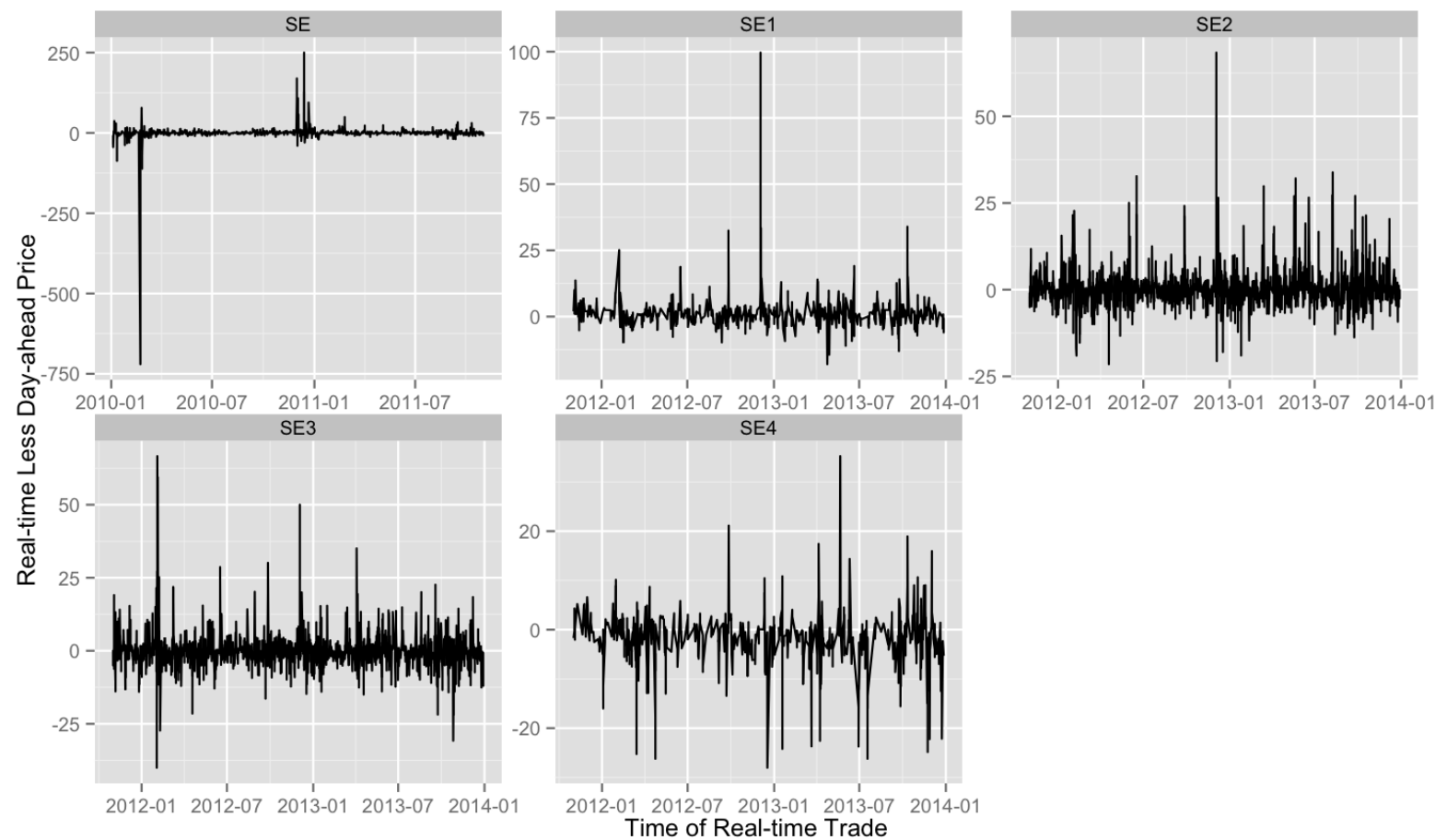

Figure 3: Real-time less day-ahead price series before and after Swedish price area reform
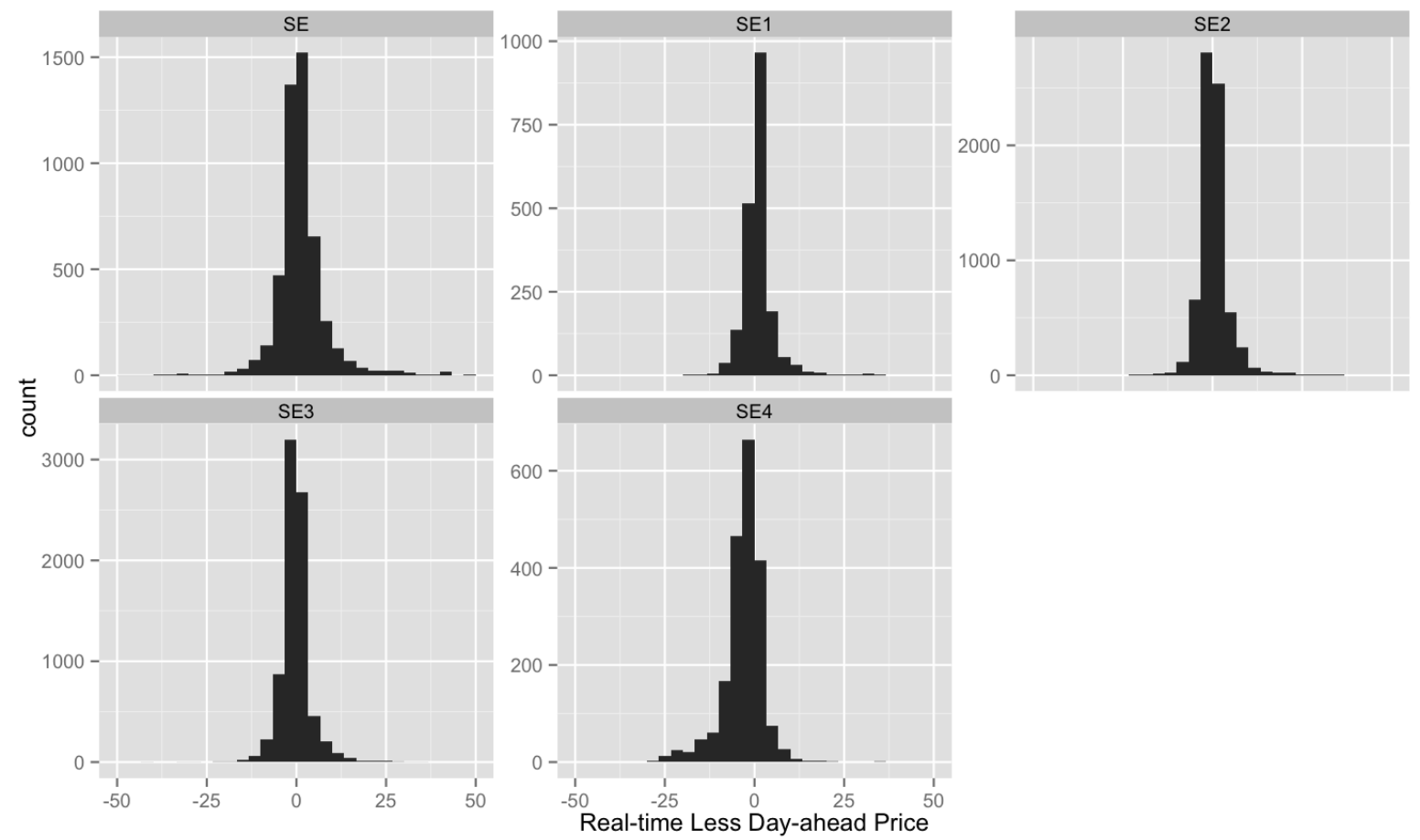

Figure 4: Histograms of real-time less day-ahead price series before and after the Swedish price area reform 
is included, the estimated coefficient on each of these dummies can be interpreted as a separate intercept term for each price area category and is then the coefficient of interest. ${ }^{11} \boldsymbol{U} \boldsymbol{M} \boldsymbol{M}_{\boldsymbol{t}}$ represents a vector of variables for coal, hydro and nuclear power plant failures. $\boldsymbol{H} \boldsymbol{D}_{t-(t-1)}$ represents a vector of variables for the change of temperature in the four price areas between the day of delivery and the previous day. This is to control for any effect failures or an unexpected change in temperature could have between the time when bids were submitted on the day-ahead and the real-time markets. $\epsilon_{i, h, t}$ represents the error term. The reported standard errors below are calculated to be robust to heteroskedasticity and autocorrelation (HAC). We account for seasonality by estimating the regression for every separate day of the week.

$$
p_{i, h, t}^{*}-f_{h, t}^{*}=\boldsymbol{\alpha} \boldsymbol{Y}_{t}+\boldsymbol{\beta} \boldsymbol{U} \boldsymbol{M} \boldsymbol{M}_{\boldsymbol{t}}+\boldsymbol{\Phi} \boldsymbol{H} \boldsymbol{D} \boldsymbol{D}_{t-(t-1)}+\epsilon_{i, h, t}
$$

Table 2 reports the regression results. ${ }^{12}$ Hypothesis 1 is violated if and only if the intercepts are negative and statistically significant. Looking first at the intercept term prior to the price area reform, labeled SE, the average real-time price is higher than the average day-ahead price all weekdays and Saturday. The difference is statistically significant at least at the $1 \%$ level. These results are consistent with, although not evidence of, competitive pricing during the weekdays. However, the coefficient switches sign during Sundays, when the average real-time price instead is lower than the average day-ahead price. This relationship is statistically significant at the $1 \%$ level.

Considering the effect of the price reform, we see that the results differ systematically between SE-N in the north and SE-S in the south. The results for SE-N look qualitatively similar to the results for SE prior to the price area reform: The coefficients are positive all days except Sundays, when the intercept becomes negative and significant. Also, the coefficients are quantitatively smaller and in some cases insignificant compared to the pre-reform estimates. The results for SE-S are almost the opposite: The coefficients are negative and statistically significant all days of the week except Fridays, when it switches sign and is statistically significant.

In summary, the regression results reject Hypothesis 1 that the day-ahead market and the real-time market were consistently competitive during the period of examination.

\footnotetext{
${ }^{11}$ We have run separate regressions for each price area category, but the results are not materially different. This is the case also for our regression results for Hypothesis 2 below. The results are available upon request.

${ }^{12}$ Table formatting was done using the $\mathrm{R}$ package texreg (Leifeld, 2013).
} 


\begin{tabular}{lccccccc}
\hline & Monday & Tuesday & Wednesday & Thursday & Friday & Saturday & Sunday \\
\hline SE & $3.41^{* * *}$ & $2.82^{* * *}$ & $2.00^{* * *}$ & $3.05^{* * *}$ & $1.80^{* * *}$ & $1.13^{* * *}$ & $-0.39^{* *}$ \\
& $(0.28)$ & $(0.36)$ & $(0.24)$ & $(0.32)$ & $(0.25)$ & $(0.18)$ & $(0.14)$ \\
SE-N & 0.27 & 0.53 & $1.38^{* * *}$ & 0.35 & $0.71^{* * *}$ & $0.81^{* * *}$ & $-0.78^{* * *}$ \\
& $(0.23)$ & $(0.30)$ & $(0.19)$ & $(0.22)$ & $(0.14)$ & $(0.12)$ & $(0.10)$ \\
SE-S & $-1.46^{* * *}$ & $-0.83^{* *}$ & $-0.67^{* * *}$ & $-0.68^{* * *}$ & $0.58^{* * *}$ & $-0.44^{* *}$ & $-1.43^{* * *}$ \\
& $(0.20)$ & $(0.27)$ & $(0.17)$ & $(0.21)$ & $(0.15)$ & $(0.15)$ & $(0.09)$ \\
ummHydro & -0.17 & -0.98 & 0.19 & $-10.03^{* * *}$ & -0.50 & $2.50^{* * *}$ & -0.29 \\
& $(0.49)$ & $(0.65)$ & $(0.50)$ & $(0.78)$ & $(0.43)$ & $(0.39)$ & $(0.38)$ \\
ummNuclear & -1.28 & -1.59 & 1.27 & -1.64 & 1.75 & $-1.80^{*}$ & $4.19^{* * *}$ \\
& $(0.87)$ & $(0.94)$ & $(0.72)$ & $(0.96)$ & $(1.63)$ & $(0.85)$ & $(0.73)$ \\
ummCoal & 0.03 & $2.56^{* * *}$ & -1.12 & $2.50^{* *}$ & 0.21 & $1.19^{*}$ & 0.33 \\
& $(0.67)$ & $(0.75)$ & $(0.70)$ & $(0.78)$ & $(0.49)$ & $(0.53)$ & $(0.41)$ \\
HDDSE1 t - (t-1) & 0.15 & 0.05 & 0.04 & $-0.21^{* * *}$ & $0.09^{* *}$ & $0.15^{* * *}$ & 0.00 \\
& $(0.08)$ & $(0.06)$ & $(0.04)$ & $(0.05)$ & $(0.03)$ & $(0.04)$ & $(0.02)$ \\
HDDSE2 t - (t-1) & $0.21^{* * *}$ & $0.29^{* *}$ & 0.09 & $0.53^{* * *}$ & $-0.26^{* * *}$ & $-0.16^{* * *}$ & $-0.16^{* * *}$ \\
& $(0.06)$ & $(0.09)$ & $(0.05)$ & $(0.05)$ & $(0.04)$ & $(0.04)$ & $(0.03)$ \\
HDDSE3 t - (t-1) & -0.09 & $-0.73^{* * *}$ & $-0.36^{* * *}$ & $-0.92^{* * *}$ & -0.10 & $0.24^{* * *}$ & $-0.08^{*}$ \\
& $(0.08)$ & $(0.10)$ & $(0.06)$ & $(0.10)$ & $(0.05)$ & $(0.04)$ & $(0.03)$ \\
HDDSE4 t - (t-1) & $0.57^{* * *}$ & $1.02^{* * *}$ & $0.52^{* * *}$ & $0.33^{* * *}$ & $0.30^{* * *}$ & $-0.26^{* * *}$ & $0.20^{* * *}$ \\
& $(0.09)$ & $(0.10)$ & $(0.06)$ & $(0.09)$ & $(0.06)$ & $(0.05)$ & $(0.04)$ \\
\hline $\mathrm{R}^{2}$ & 0.07 & 0.06 & 0.06 & 0.11 & 0.05 & 0.08 & 0.11 \\
Adj. R $\mathrm{R}^{2}$ & 0.07 & 0.06 & 0.06 & 0.10 & 0.05 & 0.08 & 0.10 \\
Num. obs. & 3864 & 3406 & 3634 & 3382 & 3191 & 3079 & 3382 \\
\hline HAC Standard Errors in parenthesis, & $p<0.001, * *$ & $<0.01,{ }^{*} p<0.05$ & &
\end{tabular}

Table 2: Empirical test of Hypothesis 1.

Hypothesis 2 To explore the second hypothesis, we first create the series $S_{i, h, t}=\left(E_{t}\left[Q_{h, t+1}^{*}\right]-\right.$ $\left.Q_{h, t}^{*}\right)\left(f_{h, t+1}^{*}-p_{i, h, t}^{*}\right)$, the difference between expected production of hour $h$ at day $t+1$ and actual production hour $h$ of day $t$ multiplied by the day-ahead price (Elspot) for delivery hour $h$ of day $t+1$ less the real-time price (Elbas) for delivery at day $t$. The series is plotted in Figure 5 for price area Sweden (SE prior to the reform) and the four price areas SE1-SE4 subsequent to the reform. The series again appears to revert towards zero, though the distribution of the series appears to be positively skewed in SE, SE1 and SE2. SE3 and SE4 appear to be more balanced. This is more clearly seen in a histogram of the observations in Figure 6. Again, the series can be shown to be stationary, however the series is autocorrelated and the variance of the series clearly varies over time (heteroskedasticity).

We use $S_{i, h, t}$ as the left-hand side of the regression represented by equation (16), while on the right-hand side we again include a vector of dummy variables representing price areas before and after the price area reform, $\boldsymbol{Y}_{t}$. The coefficients on these dummy variables can again be interpreted as separate intercept terms for the different price areas and are the coefficients of interest. $\boldsymbol{U} \boldsymbol{M} \boldsymbol{M}_{\boldsymbol{t}}$, representing power plant failures, was defined as in the previous regressions. The vector $\boldsymbol{H} \boldsymbol{D} \boldsymbol{D}_{t-(t+1)}$ again represents a vector of temperature differences in the four price areas, though notice that this time the variables are defined as the differences between the contemporaneous and day-ahead average temperature in heating degree days units in order to match the difference in delivery date between the real-time and day-ahead market in the series. $\epsilon_{i, h, t}$ represents the error term. Again, separate regressions are run for each day of the week. As the trades included in the series occur between 8 and 12 and bids for the day-ahead market are 


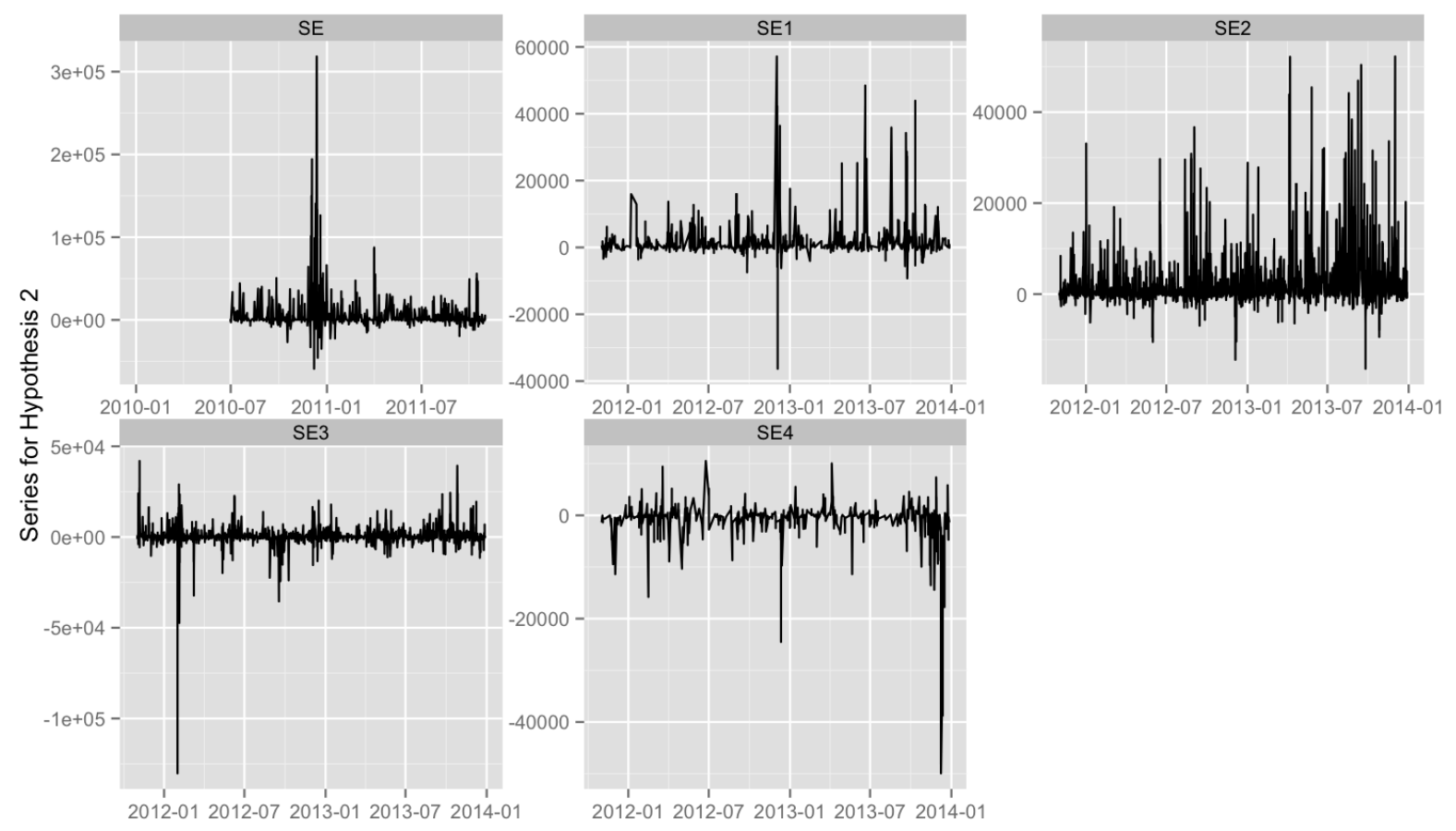

Figure 5: Hypothesis 2 series for before and after Swedish price-area reform
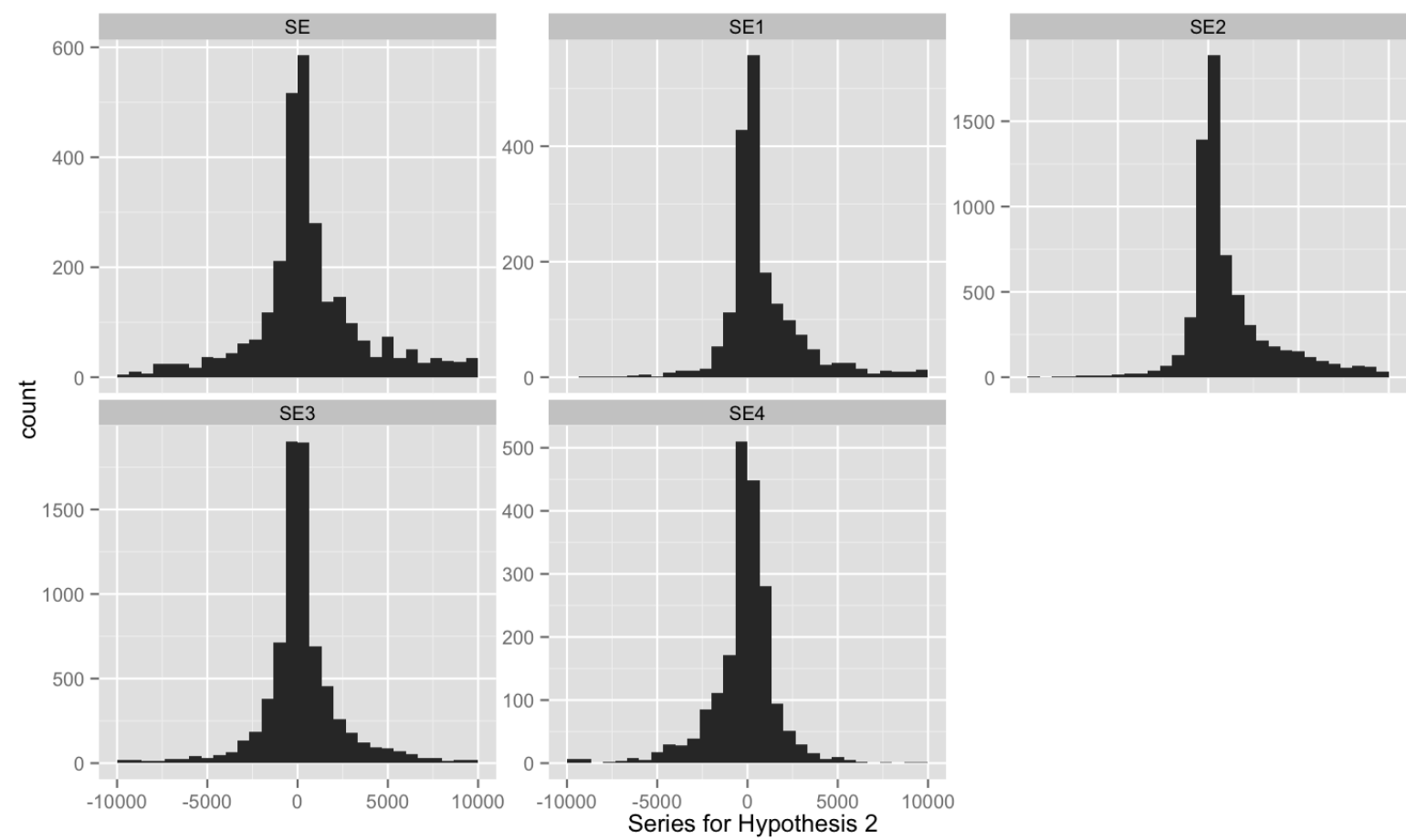

Figure 6: Histogram of the Hypothesis 2 series before and after the Swedish price-area reform 
submitted at 12 , the information available to the market participants should be nearly identical in the two markets.

$$
S_{i, h, t}=\gamma \boldsymbol{Y}_{\boldsymbol{t}}+\boldsymbol{\beta} \boldsymbol{U} \boldsymbol{M} \boldsymbol{M}_{\boldsymbol{t}}+\boldsymbol{\Phi} \boldsymbol{H} \boldsymbol{D} \boldsymbol{D}_{t-(t+1)}+\epsilon_{i, h, t}
$$

Table 3 displays the regression results. The estimated intercepts for the pre-price area reform, labeled SE, are all significantly positive, except for the coefficient on Tuesday, which is estimated to be negative, but insignificantly different from zero. The intercept comes out with a much higher coefficient on Friday and Sunday. In the first instance, this is due to a significant drop in production from Friday to Saturday and a correspondingly higher real-time price on Friday than the day-ahead price for delivery on Saturday. The Sunday coefficient picks up the production increase from Sunday to Monday, and the day-ahead price for delivery on Monday is higher than the real-time price on Sunday. What is interesting to note is that the price differences tend to be of the same sign as the expected production changes also for the other days. Although average production changes can be indiscernible from one weekday to the next, see Figure 1, the market still seems to price these anticipated production changes.

Looking at the coefficients for SE-N in the north and SE-S in the south, the prices in these two regions again provide an interesting contrast to one another. SE-N is qualitatively similar to SE, except all coefficients are now positive and statistically significant. SE-S, on the other hand, has positive coefficients on Friday and Sunday, but the coefficients are actually negative all other days, and significant Mondays, Tuesdays and Saturdays.

The coefficients on the reported failures and temperature changes are significant on various weekdays. This seems puzzling as the failures and temperature changes are realized subsequent to the prices being cleared in the market. In reality, the measured temperature differences could be predicted and therefore correlated with the expected production changes. When it comes to the UMMs, they all relate to unscheduled failures which should be uncorrelated with expected output and price differences. But it might be the case that the failure reports are in fact nonrandom and instead a function of past prices. This would be alarming from a competition point of view. However, we do not undertake a deeper analysis of the relationship between prices and UMMs here, but refer instead to Fogelberg and Lazarczyk (2014) for an empirical analysis.

In summary, the regression results reject Hypothesis 2 that the day-ahead market and the real-time market were consistently competitive during the period of examination. 


\begin{tabular}{|c|c|c|c|c|c|c|c|}
\hline & Monday & Tuesday & Wednsday & Thursday & Friday & Saturday & Sunday \\
\hline $\mathrm{SE}$ & $\begin{array}{c}2057.42^{* * *} \\
(204.47)\end{array}$ & $\begin{array}{l}-366.87 \\
(291.82)\end{array}$ & $\begin{array}{c}2814.02^{* * *} \\
(265.28)\end{array}$ & $\begin{array}{c}3545.72^{* * *} \\
(301.19)\end{array}$ & $\begin{array}{c}18996.17^{* * *} \\
(576.81)\end{array}$ & $\begin{array}{c}989.49^{* * *} \\
(159.26)\end{array}$ & $\begin{array}{c}20253.31^{* * *} \\
(805.69)\end{array}$ \\
\hline SE-N & $\begin{array}{c}703.31^{* * *} \\
(139.31)\end{array}$ & $\begin{array}{c}988.27^{* * *} \\
(205.98)\end{array}$ & $\begin{array}{l}404.73^{*} \\
(172.50)\end{array}$ & $\begin{array}{c}1267.28^{* * *} \\
(186.15)\end{array}$ & $\begin{array}{c}2742.66^{* * *} \\
(292.16)\end{array}$ & $\begin{array}{c}1151.85^{* * *} \\
(91.34)\end{array}$ & $\begin{array}{c}7647.19^{* * *} \\
(449.04)\end{array}$ \\
\hline SE-S & $\begin{array}{c}-550.73^{* * *} \\
(123.42)\end{array}$ & $\begin{array}{c}-861.37^{* * *} \\
(181.14)\end{array}$ & $\begin{array}{l}-42.67 \\
(155.27)\end{array}$ & $\begin{array}{c}-84.37 \\
(172.19)\end{array}$ & $\begin{array}{c}1088.73^{* * *} \\
(306.25)\end{array}$ & $\begin{array}{c}-362.63^{* * *} \\
(109.02)\end{array}$ & $\begin{array}{c}2411.03^{* * * *} \\
(411.88)\end{array}$ \\
\hline ummHydro & $\begin{array}{c}1892.50^{* * * *} \\
(303.55)\end{array}$ & $\begin{array}{c}369.40 \\
(459.40)\end{array}$ & $\begin{array}{l}-623.36 \\
(473.56)\end{array}$ & $\begin{array}{c}0.27 \\
(675.16)\end{array}$ & $\begin{array}{c}-2640.47^{* *} \\
(907.63)\end{array}$ & $\begin{array}{c}1445.79^{* * * *} \\
(311.24)\end{array}$ & $\begin{array}{c}-516.34 \\
(1649.23)\end{array}$ \\
\hline ummNuclear & $\begin{array}{l}-538.62 \\
(532.55)\end{array}$ & $\begin{array}{c}117.48 \\
(650.57)\end{array}$ & $\begin{array}{c}-1141.75 \\
(679.59)\end{array}$ & $\begin{array}{c}981.29 \\
(847.69)\end{array}$ & $\begin{array}{l}-1739.35 \\
(3363.59)\end{array}$ & $\begin{array}{c}2987.61^{* * * *} \\
(644.41)\end{array}$ & $\begin{array}{c}-14016.03^{* * *} \\
(3219.89)\end{array}$ \\
\hline ummCoal & $\begin{array}{c}106.37 \\
(401.14)\end{array}$ & $\begin{array}{c}-4404.34^{* * *} \\
(531.75)\end{array}$ & $\begin{array}{l}-10.09 \\
(688.54)\end{array}$ & $\begin{array}{l}-391.31 \\
(649.52)\end{array}$ & $\begin{array}{l}2471.93^{*} \\
(1019.58)\end{array}$ & $\begin{array}{c}1232.65^{* *} \\
(429.70)\end{array}$ & $\begin{array}{c}-981.33 \\
(2486.56)\end{array}$ \\
\hline HDDSE1 $\mathrm{t}-(\mathrm{t}+1)$ & $\begin{array}{c}-114.43^{* * * *} \\
(33.88)\end{array}$ & $\begin{array}{c}138.19^{* *} \\
(45.02)\end{array}$ & $\begin{array}{c}209.81^{* * * *} \\
(42.31)\end{array}$ & $\begin{array}{l}-62.77 \\
(42.96)\end{array}$ & $\begin{array}{c}-194.35^{*} \\
(88.08)\end{array}$ & $\begin{array}{c}41.51 \\
(21.40)\end{array}$ & $\begin{array}{l}-164.81 \\
(145.46)\end{array}$ \\
\hline HDDSE2 $\mathrm{t}-(\mathrm{t}+1)$ & $\begin{array}{c}-382.54^{* * *} \\
(47.36)\end{array}$ & $\begin{array}{c}-391.05^{* * *} \\
(63.57)\end{array}$ & $\begin{array}{c}-652.73^{* * *} \\
(44.29)\end{array}$ & $\begin{array}{c}167.72^{* * *} \\
(56.38)\end{array}$ & $\begin{array}{l}113.12 \\
(80.70)\end{array}$ & $\begin{array}{l}-26.93 \\
(27.27)\end{array}$ & $\begin{array}{c}-616.20^{* * * *} \\
(118.37)\end{array}$ \\
\hline HDDSE3 $t-(t+1)$ & $\begin{array}{c}433.99^{* * *} \\
(60.94)\end{array}$ & $\begin{array}{c}163.24^{*} \\
(64.86)\end{array}$ & $\begin{array}{c}726.79^{* * *} \\
(80.75)\end{array}$ & $\begin{array}{c}766.75^{* * *} \\
(66.33)\end{array}$ & $\begin{array}{l}-203.16 \\
(115.37)\end{array}$ & $\begin{array}{c}147.57^{* * * *} \\
(35.99)\end{array}$ & $\begin{array}{c}606.52^{* * *} \\
(176.81)\end{array}$ \\
\hline HDDSE $4 \mathrm{t}-(\mathrm{t}+1)$ & $\begin{array}{c}87.77 \\
(53.93) \\
\end{array}$ & $\begin{array}{c}343.40^{* * *} \\
(73.73) \\
\end{array}$ & $\begin{array}{c}-264.06^{* * *} \\
(66.93) \\
\end{array}$ & $\begin{array}{c}-663.51^{* * * *} \\
(66.07)\end{array}$ & $\begin{array}{c}1245.30^{* * * *} \\
(140.78)\end{array}$ & $\begin{array}{c}-167.65^{* * *} \\
(35.07)\end{array}$ & $\begin{array}{c}-1277.17^{* * *} \\
(192.03)\end{array}$ \\
\hline$\overline{\mathrm{R}^{2}}$ & 0.10 & 0.05 & 0.09 & 0.15 & 0.30 & 0.11 & 0.26 \\
\hline Adj. $\mathrm{R}^{2}$ & 0.09 & 0.05 & 0.09 & 0.14 & 0.30 & 0.11 & 0.26 \\
\hline Num. obs. & 3654 & 3154 & 3426 & 3239 & 3099 & 2854 & 3086 \\
\hline
\end{tabular}

Table 3: Empirical test of Hypothesis 2

\subsection{Interpretation of the results}

Our estimations partially reject Hypothesis 1 and Hypothesis 2. Still, it would be premature to conclude that the Nordic electricity market is imperfectly competitive based upon the above regression results. It could be case that the theoretical model is misspecified, in which case the estimated coefficients would not identify market power, but could rather be evidence of something else.

Buyer risk aversion We use the Nordic intraday market, Elbas, as our proxy for the realtime market. Participants in Elbas are generation companies, retailers and large energy intensive industries that rebalance their portfolios. One reasonable explanation for negative price differences could be that retailers and energy intensive industries are comparatively more risk averse than the producers and therefore prepared to pay a premium to settle their contracts in the dayahead market. The estimated coefficients provide some support for this interpretation. SE-N in the north is predominantly dominated by hydropower. It is an excess supply region exporting electricity to SE-S in the south. SE-S contains all nuclear power and most of the other thermal power in Sweden. It is an excess demand region importing electricity from SE-N and the neighbouring countries. Because of these structural differences between the regions, rebalancing in SE-N (SE-S) for the most part would imply generation companies (energy intensive industries) adjusting their supply (consumption). Hence, one might expect producer (consumer) risk aversion to dominate in SE-N (SE-S). This could explain why the real-time prices tend to be higher (lower) than the day-ahead price in SE-N (SE-S) in Table 2. However, systematic differences 
in risk aversion between regions cannot explain why price differences are positive one day and negative the other within each region. That the price difference switches sign from one day to the next is difficult to reconcile with perfect competition and risk aversion; see also Borenstein et al. (2008) for an argument along similar lines.

Marginal trading costs Another explanation for price differences other than market power could be differences in marginal trading costs between the real-time and the day-ahead market. The variable fee for trading on Elbas is $0.11 \mathrm{EUR} / \mathrm{MWh}$, while the corresponding fee is 0.04 EUR/MWh on the day-ahead market, Elspot. ${ }^{13}$ Any price difference in the range of $[-0.07,0.07]$ EUR/MWh would therefore be consistent with competitive pricing on NPS. As should be obvious from Table 2, the average price differences are well outside this range whenever the coefficients are significant. Hence, marginal trading costs cannot explain all price differences.

Thermal production The foundation for Hypothesis 2 is the intertemporal substitution of hydro production. In markets without hydro power, there would not necessarily be any systematic link between production changes and differences between the real-time price and the day-ahead price for contracts traded simultaneously. Most of the hydro power is located in SE1 and SE2. Returning to Figure 6 , we see that the variable $S_{i, h, t}$ is positively skewed in those price areas, just as one would expect. However, $S_{i, h, t}$ is more balanced in SE3 and SE4, where most of the production is nuclear or thermal. This is consistent with intertemporal decisions playing less of a role in price areas dominated by thermal production.

Thin markets A fourth explanation for the price differences could be that the observed prices on the intraday market, Elbas, would produce biased estimates of the expected real-time prices. This bias could be explained for example by a lower market liquidity at the end of the week failing to deliver "correct" market prices. In reality, the number of completed trades in the intraday market was more or less the same throughout the week during our sample period, both prior and subsequent to the price reform. If we consider the other explanatory variables, we see that neither the estimated UMM nor temperature coefficients differ much between Sunday and the other days of the week in Table 2. The substantial difference is ummNuclear which comes in positive and significant on Sundays in Table 2 and is negative or insignificant the other weekdays.

\footnotetext{
${ }^{13}$ Market participants also have to pay an annual fee, plus there are fixed overhead costs associated with trading in the two markets. However, only differences in marginal trading costs should have a bearing on the price differences. See www.nordpoolspot.com/TAS/Fees/for an overview of the current trading fees at NPS.
} 
However, that a nuclear power plant outage subsequent to gate closure of the day-ahead market should drive up the real-time price, is hardly an anomaly. Returning to Table 3 , we also see that real-time and day-ahead prices move in tandem with expected production changes in SN-N throughout the week, just as one might expect. Overall, these observations lend support to a conclusion that prices are driven by rational bidding rather than non-rational market behaviour.

Market power We reject the joint hypothesis that prices at Nord Pool Spot were at their competitive levels throughout the period under examination. Still, the question remains as to whether the observed price differences can reflect market power.

Consider first the estimated coefficients in Table 2. If the producers are risk neutral, then the optimality condition (12) becomes

$$
E_{t}\left[p_{t+1}^{*}\right]-f_{t+1}^{*}=\frac{\partial F_{t+1}^{*}}{\partial z_{t}} z_{t}^{*}+E_{t}\left[\left(\frac{\partial P_{t+1}^{*}}{\partial z_{t}}-\frac{\partial P_{t+1}^{*}}{\partial x_{t+1}}\right) x_{t+1}^{*}\right]
$$

Under the assumption that the average Elbas price is an unbiased estimate of the expected realtime price in the Nordic electricity market, the left-hand side of the above equation has been estimated to be strictly negative on Sundays in SE prior to the reform and in SE-N subsequent to the reform. In the polar case of perfect competition in the real-time market $\left(\frac{\partial P_{t+1}^{*}}{\partial z_{t}}=\frac{\partial P_{t+1}^{*}}{\partial x_{t+1}}=0\right)$, the estimated price difference is consistent with the exercise of market power in the day-ahead market, whereby sellers withhold output to increase the day-ahead price on Saturdays (for delivery on Sundays).

Transmission constraints often are non-binding during weekends because of low demand. The day-ahead market therefore displays a large degree of integration between the different price areas on Saturdays and Sundays. Hence, one might expect competition in the day-ahead market to be more intense during weekends and market power less of a problem than otherwise. In the other polar case of perfect competition in the day-ahead market $\left(\frac{\partial F_{t+1}^{*}}{\partial z_{t}}=0\right)$, the price difference is still consistent with the exercise of market power. One possibility is that producers reduce day-ahead supply in order to shift demand to the real-time market and thereby increase the real-time price. Alternatively, producers can be systematically over-contracted in the realtime market $\left(x_{t+1}^{*}<0\right)$ so that they exercise market power by withholding demand in order to decrease the real-time price on Sundays.

An explanation for why Hypothesis 1 would be rejected late in the week in SE-N and not otherwise relies on risk aversion. Suppose that market power in the day-ahead market and 
risk aversion both prevail throughout the week. Prices are substantially more volatile during the weekdays than the weekend. Risk aversion might then dominate at the beginning of the week, yielding higher real-time than day-ahead prices during the weekdays. Instead, market power might be more influential later in the week when prices are more stable, thus generating negative price differentials during the weekend.

Consider next the estimated coefficients in Table 3. Multiplying both sides of the the optimality condition (14) by the differences in expected production, we obtain

$$
\begin{aligned}
\left(E_{t}\left[Q_{t+1}^{*}\right]-Q_{t}^{*}\right)\left(f_{t+1}^{*}-p_{t}^{*}\right) & =\left(E_{t}\left[Q_{t+1}^{*}\right]-Q_{t}^{*}\right)\left\{\frac{\partial P_{t}^{*}}{\partial x_{t}} x_{t}^{*}-E_{t}\left[\left(\frac{\partial P_{t+1}^{*}}{\partial z_{t}}+\frac{\partial P_{t+1}^{*}}{\partial r_{n t}}\right) x_{t+1}^{*}\right]-\left(\frac{\partial F_{t+1}^{*}}{\partial z_{t}}+\frac{\partial F_{t+1}^{*}}{\partial r_{n t}}\right) z_{t}^{*}\right\} \\
& +\left(E_{t}\left[Q_{t+1}^{*}\right]-Q_{t}^{*}\right) \frac{\bar{x}_{n t}^{*}-\underline{\chi}_{n t}^{*}+E_{t}\left[\underline{\chi}_{n(t+1)}^{*} \underline{R}_{n}^{\prime}\left(r_{n t}^{*}\right)\right]-E_{t}\left[\bar{\chi}_{n(t+1)}^{*} \bar{R}_{n}^{\prime}\left(r_{n t}^{*}\right)\right]+\underline{\lambda}_{t}^{*}-\bar{\lambda}_{t}^{*}}{\beta E_{t}\left[U^{\prime}\left(c_{t+1}^{*}\right)\right]}
\end{aligned}
$$

under risk neutrality. We have estimated the left-hand side of (18) to switch signs between the different days of the week in SE-S. The term on the second line above is non-negative. In the polar case of perfect competition in the real-time (day-ahead) market, the fluctuations are consistent with imperfect competition in the day-ahead (real-time) market and changes in the sign of $E_{t}\left[Q_{t+1}^{*}\right]-Q_{t}^{*}$ between days. Notwithstanding Hypothesis 2, we are reluctant to interpreting these fluctuations as evidence of market power in southern Sweden, because SE-S consists mainly of nuclear and other thermal production, thereby questioning the validity of (18) in SE-S.

Equations (17) and (18) reveal a limitation of the diagnostic tests we have proposed. The left-hand side of both equations has been estimated to be strictly positive on weekdays in SE and SE-N. This is consistent with perfect competition, risk-aversion and binding production or reservoir constraints, but it is also consistent with perfect competition in the day-ahead market and producers exercising market power by withholding supply from the real-time market. This would not be an unlikely scenario given the limited number of participants in the real-time market and the relatively small volumes traded there. In this case, Hypothesis 1 would always be accepted, whereas Hypothesis 2 would be be accepted insofar as the expected constraints would dominate market power in the estimations. ${ }^{14}$ Consequently, the tests proposed in this paper should only be seen as a first test of market performance and are no by no means perfect substitutes for more detailed tests based upon, say, observed bidding behaviour.

\footnotetext{
${ }^{14}$ While Hypothesis 2 does not necessarily represent as strong test of market performance, it still provides relevant information as to whether the real-time and day-ahead market prices behave in a manner consistent with the theoretical model.
} 


\section{Conclusion}

This paper has analysed in a theoretical framework the link between day-ahead and real-time market performance in a hydro-based wholesale electricity market. We have derived tests of market performance directly from the first-order conditions and applied them to evaluate the Nordic power exchange, Nord Pool Spot (NPS). Our results reject the null hypothesis that NPS was characterized by perfect competition in all markets throughout the period of investigation.

The informational requirements of the methodology are mild. We only use equilibrium prices and production. Individual bid data are not necessary, nor is it necessary to estimate demand and marginal cost functions. We control for risk aversion because the model builds upon expected utility maximization as its behavioral assumption.

Owing to its simplicity, the methodology necessarily brings with it some drawbacks. It is only a diagnostic test of whether the market can be considered competitive. In case of rejection, it is impossible to estimate markups without more detailed data. Also, we run the risk of underestimating market power because price relations consistent with perfect competition are also consistent with the exercise of market power. Hence, the methods proposed in this paper are by no means perfect substitutes for elaborate simulation models or estimation methods built upon detailed bid data. Rather, we see the methodology as a first and relatively simple step in the analysis of the performance of hydro-based electricity markets.

\section{References}

Allaz, B. and J.-L. Vila (1993): Cournot competition, forward markets and efficiency. Journal of Economic Theory 59, 1-16.

Bask, M., J. Lundgren and N. Rudholm (2011): Market power in the expanding Nordic power market. Applied Economics 43, 1035-1043.

Bessembinder H. and M.L. Lemmon (2002): Equilibrium pricing and optimal hedging in electricity forward markets. Journal of Finance 57, 1347-1382.

Blanchard, O.J. and S. Fischer (1989): Lectures on Macroeconomics. Cambridge, MA: MIT Press. 
Borenstein, S., J. Bushnell, C.R. Knittel and C. Wolfram (2008): Inefficiencies and market power in financial arbitrage: A study of California's electricity markets. Journal of Industrial Economics LVI, 347-378.

Borenstein, S., J. Bushnell and F.A. Wolak (2002): Measuring market inefficiencies in California's restructured wholesale electricity market. American Economic Review 92, 1376-1405.

Bushnell, J. (2003): A mixed complementarity problem of hydrothermal electricity competition in the western United States. Operations Research 51, 80-93.

Bushnell, J.B., E.T. Mansur and C. Saravia (2008): Vertical arrangements, market structure, and competition: An analysis of restructured US electricity markets. American Economic Review $98,237-266$.

Fogelberg, S. and E Lazarczyk (2014): Strategic withholding through production failures. IFN Working Paper No. 105.

Førsund, F.R. (2007): Hydro Power Economics. New York, NY: Springer.

Crampes, C. and M. Moreaux (2001): Water resource and power generation. International Journal of Industrial Organization 19, 975-997.

Garcia, A., J.D. Reitzes and E. Stacchetti (2001): Strategic pricing when electricity is storable. Journal of Regulatory Economics 20, 223-247.

Graf, G. and D. Wozabal (2013): Measuring competitiveness of the EPEX spotmarket for electricity. Energy Policy 62, 948-958.

Hansen, P.V. (2009): Inflow uncertainty in hydro power markets. Scandinavian Journal of Economics 111, 189-207.

Holmberg, P. (2008): Unique supply function equilibrium with capacity constraints. Energy Economics 30, 148-172.

Holmberg, P. (2011): Strategic forward contracting in the wholesale electricity market. Energy Journal 32, 169-202. 
Hughes, J.S. and J.L. Kao (1997): Strategic forward contracting and observability. International Journal of Industrial Organization 16, 121-133.

Jha, A. and F.A. Wolak (2014): Testing for market efficiency with transaction costs: An application to convergence bidding in wholesale electricity markets. Manuscript Stanford University, Accessed from http://www.stanford.edu/group/fwolak/cgi-bin/?q=node/3 June 3, 2014.

Johnsen, T.A. (2001): Hydro power generation and storage, transmission constraints and market power. Utilities Policy 10, 63-73.

Kauppi, O. and M. Liski (2008): An empirical model of imperfect dynamic competition and application to hydroelectricity storage. HECER Discussion Paper 232.

Kim, D.-W. and C. Knittel (2006): Biases in static oligopoly models? Evidence from the California electricity market. Journal of Industrial Economics 54, 451-470.

Klemperer, P.D. and M.A. Meyer (1989): Supply function equilibria in oligopoly under uncertainty. Econometrica 57, 1243-1277.

Leifeld, P. (2013): texreg: Conversion of statistical model output in R to $\mathrm{IAT}_{\mathrm{E} X} \mathrm{and}$ HTML tables. Journal of Statistical Software 55, 1-24.

Mahenc, P., and F. Salanié (2004): Softening competition through forward trading. Journal of Economic Theory 116, 282-293.

Mathiesen, L., J. Skaar and L. Sørgard (2013): Electricity production in a hydro system with a reservoir constraint. Scandinavian Journal of Economics 115, 575-594.

McRae, S.D. and F.A. Wolak (2009): How do firms exercise unilateral market power? Evidence from a bid-based wholesale electricity market. Manuscript, Stanford University. Accessed from http://www.stanford.edu/group/fwolak/cgi-bin/?q=node/3 June 3, 2014. 
NordREG (2013): Nordic market report 2013. Report 6/2013.

Philpott, A., Z. Guan, J. Khazaei and G. Zakeri (2010): Production inefficiency of electricity markets with hydro generation. Utilities Policy 18, 174-185.

R Core Team (2013). R: A Language and Environment for Statistical Computing. Vienna: R Foundation for Statistical Computing. Accessed from www.R-project.org June 26, 2014.

Wickham, H. (2009): ggplot2: Elegant Graphics for Data Analysis. New York, NY: Springer.

Wolak, F.A. (2003): Measuring unilateral market power in electricity wholesale markets: The California market, 1998-2000. American Economic Review Papers and Proceedings 93, 425-430. Wolfram, C. (1999): Measuring duopoly power in the British electricity spot market. American Economic Review 89, 805-826. 